\title{
Optimal Monetary Policy Rules, Asset Prices and Credit Frictions *
}

\author{
Ester Faia ${ }^{\dagger}$ \\ Universitat Pompeu Fabra
}

\author{
Tommaso Monacelli ${ }^{\ddagger}$ \\ IGIER, Università Bocconi and CEPR
}

January 2005

\begin{abstract}
We study optimal monetary policy in two prototype economies with sticky prices and credit market frictions. In the first economy, credit frictions apply to the financing of the capital stock, generate acceleration in response to shocks and the "financial markup" (i.e., the premium on external funds) is countercyclical and negatively correlated with the asset price. In the second economy, credit frictions apply to the flow of investment, generate persistence, and the financial markup is procyclical and positively correlated with the asset price. We model monetary policy in terms of welfare-maximizing interest rate rules. The main finding of our analysis is that strict inflation stabilization is a robust optimal monetary policy prescription. The intuition is that, in both models, credit frictions work in the direction of dampening the cyclical behavior of inflation relative to its credit-frictionless level. Thus neither economy, despite yielding different inflation and investment dynamics, generates a trade-off between price and financial markup stabilization. A corollary of this result is that reacting to asset prices does not bear any independent welfare role in the conduct of monetary policy.
\end{abstract}

Keywords: Optimal monetary policy rules, financial distortions, price stability, asset prices.

\footnotetext{
${ }^{*}$ First draft May 2004. We thank Pierpaolo Benigno, Fiorella de Fiore, Harris Dellas, Jordi Galí, Stephanie Schmitt-Grohe, Michael Woodford and participants to the 2004 ESSIM-CEPR conference for useful comments. All errors are our own responsibility.

${ }^{\dagger}$ Correspondence to Universitat Pompeu Fabra, Ramon Trias Fargas 25, Barcelona, Spain. E-mail: ester.faia@econ.upf.es, homepage: http://www.econ.upf.es/ faia/.

${ }^{\ddagger}$ Correspondence to IGIER Universita’ Bocconi, Via Salasco 3/5, 20136 Milan, Italy. Email: tommaso.monacelli@uni-bocconi.it, Tel: +39-02-58363330, Fax: +39-02-58363332, Web page: www.igier.unibocconi.it/monacelli.
} 


\section{Introduction}

In this paper we study optimal monetary policy rules in an economy with nominal rigidities and credit market imperfections. Our interest is twofold. First, we aim at driving the attention of the recent literature on a typology of market distortions whose role has been largely neglected in the normative analysis of monetary policy. This is surprising, considering the increasing emphasis placed on financial factors in the studying of business cycles (starting with Bernanke and Gertler (1989)). Second, we aim at assessing - from a welfare-based perspective - the role that asset prices and or other financial indicators should play in the optimal setting of monetary policy rules.

The latter issue has been recently the object of an intense debate, within both policy and academic circles, in light of the asset price inflation phenomenon of the late nineties, followed by the burst of the alleged financial bubble at the beginning of the new century. ${ }^{1}$ However, the theoretical literature linking asset prices, monetary policy and financial frictions in dynamic general equilibrium models has been scant. Bernanke and Gertler (2001) (BG henceforth) compare the performance of alternative interest rate rules, including some that feature a reaction to asset price movements. Their main conclusion is that there is negligible stabilization gain from including asset prices as independent arguments in the rules. Gilchrist and Leahy (2002) employ a similar (financial accelerator) framework, and evaluate the ability of alternative rules to have their reference model mimic as close as possible the dynamics of a real business cycle model. Cecchetti et al. (2002) contend with BG, and argue that the desirability of including asset prices as separate arguments in interest rate rules is likely to depend on the underlying source of shocks. ${ }^{2}$

The common shortcoming of this literature is that it completely abstracts from strict welfare considerations. The metric adopted for the evaluation of the relative performance of policy rules is typically an output-inflation volatility frontier. This makes it hard to correctly rank alternative specifications for monetary policy, and to safely draw normative conclusions about the desirability for monetary policy to react to asset price movements. It is this consideration that essentially motivates the present paper.

A common argument of the contenders of the BG view is that asset price movements may be driven by non-fundamental shocks to the financial side of the economy - i.e., bubbles - and that a monetary authority which aims at reaching a first-best allocation should convey those movements back to their efficient evolution. ${ }^{3}$ However, it seems hard to justify a systematic response of the monetary authority to asset price movements only on the possibility of occurrence of bubble

\footnotetext{
${ }^{1}$ See Gilchrist and Leahy (2002) for a survey.

${ }^{2}$ Iacoviello (2004) analyzes monetary policy in a model with credit cycles a la Kyotaki and Moore (1997) and housing, and concludes that reacting to asset prices does not improve macroeconomic stability.

${ }^{3}$ See also Dupor (2003).
} 
dynamics (Bernanke 2002). For this reason we re-focus the analysis in a more genuine public finance spirit and solely in the presence of fundamental shocks (e.g., to productivity and/or government expenditures).

Our baseline economy will feature three types of distortions. First, monopolistic competition in goods markets, which forces average output below the socially optimal level. Second, adjustment costs in nominal goods prices, which entail a direct resource cost, as well as a misalignment between the marginal utility of consumption and leisure due to time variations in price markups. Third, informational frictions, in the form of endogenous agency costs, which characterize the relationship between borrowers and lenders in the credit market. In this context, and in deviation from the Modigliani-Miller theorem, the evolution of firms' net worth affects both the cost of access to credit and the price of capital. Yet, in turn, these developments feedback onto firms' financial position, further affecting investment and capital accumulation. Agency costs, per se, have a twofold effect. In the long run, they produce an inefficiently low level of capital, and hence output, since the economy suffers a deadweight loss associated to the monitoring activity of the lender. In the shortrun, the presence of a time-varying "financial markup" distorts the dynamic allocation of capital and investment.

The recent optimal monetary policy literature has dealt with the role of distortions in alternative ways. The vast majority of papers specify a complementary (and arguably unrealistic) role of fiscal policy to neutralize the steady-state distortions related to market power in goods and/or labor markets. This assures that, if the only left distortion is price stickiness, the average level of output coincides (under zero inflation) also with the efficient one, allowing to neglect the role of stochastic uncertainty on the mean level of those variables which are relevant for welfare. ${ }^{4}$ The approach followed here, as in Kollmann (2003a, 2003b) and Schmitt-Grohe and Uribe (2003, 2004b), and unlike much of the so-called New Keynesian literature, allows to study optimal policy in a dynamic economy that evolves around a steady-state which remains distorted. Importantly, in our context, the steady state of the economy will be distorted not only by the presence of nominal rigidities and market power in goods markets, but also by the presence of monitoring costs in credit markets. As emphasized by Kim et al. (2003) and Schmitt-Grohe and Uribe (2004b), this strategy requires that an accurate evaluation of welfare be based on a higher order approximation of all the conditions that characterize the competitive equilibrium of the economy. ${ }^{5}$

\footnotetext{
${ }^{4}$ To name a few, Rotemberg and Woodford (1997), Clarida, Gali and Gertler (1999), King and Wolman (1999), Erceg, Henderson and Levin (2000), culminating with Woodford (2003).

${ }^{5}$ Alternatively, Benigno and Woodford (2004) show how to preserve the linear-quadratic form of an optimal policy problem in the case in which the economy fluctuates around a non-efficient steady-state. This per se requires taking a second order approximation of (some of) the underlying equilibrium conditions.
} 


\subsection{Credit Frictions and Financial Markups: Two Theoretical Frameworks}

We will articulate our analysis of optimal monetary policy on two general equilibrium models in which credit market frictions and asset price movements play a role. The first model is based on Bernanke, Gertler and Gilchrist (1999), while the second model is a sticky-price monetary extension of Carlstrom and Fuerst (1997). The common denominator to the two models is that credit frictions take the form of endogenous agency costs in the relationship between lenders and borrowers (typically entrepreneurs). These costs emerge when verifying the return of borrowers' (risky) projects is costly for the lender, a feature that generates a typical moral hazard problem. ${ }^{6}$

There are however important differences. In the first framework, labelled below as capitalacceleration model ( $K A$ model henceforth), credit frictions apply to the financing of the stock of capital owned by entrepreneurs. In equilibrium, firms face a spread between the cost of internal and external funds (the external finance premium). The key element of this model lies in the countercyclical behavior of the finance premium, a mechanism that generates an effect of acceleration in response to shocks. Movements in asset prices act to reinforce this mechanism, by affecting the value of the capital stock and hence entrepreneurs' balance sheets. This asset price effect is akin to the credit-cycle phenomenon stressed by Kyotaki and Moore (1997). The main regularity we are interested in singling out in this model is that, as a result, asset prices and finance premium are negatively correlated.

The second model we analyze is labelled investment-propagation model (IP henceforth). In this framework, credit frictions apply to the financing of the investment flow. Two are the main differences with respect to the KA model. First, rather than acceleration, the IP model generates equilibrium propagation of shocks (i.e., hump-shaped dynamics of output and investment). This difference stems crucially from the equilibrium sluggish behavior of entrepreneurs' net worth. This feature is such that, e.g., a rise in productivity, brings about an initial rise in borrowing needs and therefore in the marginal cost of investment. However, as net worth accumulates over time, it generates a corresponding shift in the investment supply curve, thereby subsequently lowering the marginal cost of investment. This effect generates a second crucial difference in the IP model, namely that the external finance premium behaves procyclically, and is directly proportional to the behavior of the relative price of investment goods (asset price). Thus, asset price and finance premium are positively correlated in this framework.

An important consequence is that the interpretation of asset price movements differs in the two models. In the KA model, fluctuations in asset prices are introduced somewhat exogenously. More precisely, they would disappear in the absence of adjustment costs on capital (a scenario that

\footnotetext{
${ }^{6}$ In turn, all these models are extensions of the seminal contribution of Bernanke and Gertler (1989) who incorporate in general equilibrium the costly state verification framework of Gale and Hellwig (1985).
} 
would not correspond to the absence of credit frictions $)^{7}$. Rather, in the IP model, movements in the Tobin's q are genuinely endogenous, in the sense that they relate fundamentally to the presence of investment financing frictions.

Therefore, and more importantly for our purposes, the public finance interpretation of asset price movements differs in the two models. In the IP model, unlike the KA model, asset price fluctuations are akin to financial markups cyclical variations. In fact, investment goods must sell at a markup over consumption goods to compensate the lender for the costs of imperfect monitoring. In this respect, their behavior resembles the one of a tax affecting the intertemporal allocation of investment. The corresponding financial markup concept in the KA model is the external finance premium on the amount borrowed in excess of internal funds. In equilibrium, capital accumulation must be such that the marginal cost of external funds is equated to the rate of return on capital. Hence, in this case, a markup is applied to a relative return as opposed to a relative price.

The main finding of our analysis is that strict inflation stabilization is a robust optimal monetary policy prescription. Noticeably, this holds regardless of the two models delivering opposite predictions on the cyclical behavior of the financial markup. The basic intuition works as follows. Although the dynamics of inflation and investment differ sharply across models, we find that in both cases credit frictions work in the direction of dampening the cyclical behavior of inflation relative to a hypothetical environment in which the same frictions are absent. Hence, when credit frictions generate acceleration and over-investment (as in the KA model) we find that inflation falls below its steady state but, at the margin, it rises relative to its level in the absence of credit frictions. On the other hand, when credit frictions generate persistence and, in the short run, keep investment below its credit-frictionless level (as in the IP model), also inflation remains below its credit-frictionless benchmark. In both cases, a manipulation of the real interest rate does not generate any inherent trade-off between stabilizing the price markup and stabilizing the financial markup. A corollary of this result is that reacting to asset prices does not bear any independent welfare role in the conduct of monetary policy.

The remainder of the paper is organized as follows. Section 2 and 6 introduces the main differences in the theoretical frameworks analyzed in the paper. Section 3 describes our calibration and solution strategy. Section 4 presents results on the equilibrium dynamics.. Section 5 illustrates our welfare metric and section 7 concludes.

\footnotetext{
${ }^{7}$ This does not deny of course that movements in asset prices are magnified in the KA model due to an endogenous interaction with firms' balance sheets.
} 


\section{Capital-Acceleration (KA) Model}

The first model we analyze builds on Bernanke, Gertler and Gilchrist (1999) financial accelerator model. We will present this framework in more detail, while later on emphasizing only the basic differences in the IP model. ${ }^{8}$

\subsection{Households (Lenders)}

There is a continuum of households, each indexed by $i \in(0,1)$. They consume a composite final good, invest in safe bank deposits, supply labor, and own shares of a monopolistic competitive sector that produces differentiated varieties of goods. The representative household chooses the set of processes $\left\{C_{t}, N_{t}\right\}_{t=0}^{\infty}$ and one-period nominal deposits $\left\{D_{t}\right\}_{t=0}^{\infty}$, taking as given the set of processes $\left\{P_{t}, W_{t},\left(1+R_{t}^{n}\right)\right\}_{t=0}^{\infty}$ and the initial condition $D_{0}$ to maximize:

$$
\mathcal{W}_{0} \equiv E_{0}\left\{\sum_{t=0}^{\infty} \beta^{t} U\left(C_{t}, N_{t}\right)\right\}
$$

subject to the sequence of budget constraints:

$$
P_{t} C_{t}+D_{t+1} \leq\left(1+R_{t}^{n}\right) D_{t}+W_{t} N_{t}+\Upsilon_{t}+T_{t}
$$

where $C_{t}$ is workers' consumption of the final good, $W_{t}$ is the nominal wage, $N_{t}$ is total labor hours, $R_{t}^{n}$ is the nominal net interest rate paid on deposits, $\Upsilon_{t}$ are the nominal profits that households receive from running production in the monopolistic sector and $T_{t}$ are lump sum taxes/transfers from the fiscal authority. The first order conditions of the above problem read as follows:

$$
\begin{gathered}
U_{c, t}=\beta\left(1+R_{t}^{n}\right) E_{t}\left\{U_{c, t+1} \frac{P_{t}}{P_{t+1}}\right\} \\
U_{c, t} \frac{W_{t}}{P_{t}}=-U_{n, t} \\
\lim _{j \rightarrow \infty}\left(1+R_{t+j}^{n}\right)^{-1} D_{t+j}=0
\end{gathered}
$$

with the addition of (2) holding with equality.

\footnotetext{
${ }^{8}$ An alternative to the KA framework, still featuring effects of financial acceleration (or "credit cycles"), would have been the model of Kyotaki and Moore (1997). See below for a discussion of why the latter model would have been incongrous for the analysis of optimal policy conducted here.
} 


\subsection{Unfinished-Capital Producers}

A competitive sector of capital producers combine investment (expressed in the same composite as the final good, hence with price $P_{t}$ ) and existing (depreciated) capital stock to produce unfinished capital goods. This activity entails physical adjustment costs. The corresponding CRS production function is $\phi\left(\frac{I_{t}}{K_{t}}\right) K_{t}$, so that capital accumulation obeys:

$$
K_{t+1}=(1-\delta) K_{t}+\phi\left(\frac{I_{t}}{K_{t}}\right) K_{t}
$$

where $\phi(\bullet)$ is increasing and convex.

Define $Q_{t}$ as the re-sell price of the capital good. Capital producers maximize profits $Q_{t} \phi\left(\frac{I_{t}}{K_{t}}\right)$ $K_{t}-P_{t} I_{t}$, implying the following first order condition:

$$
Q_{t} \phi^{\prime}\left(\frac{I_{t}}{K_{t}}\right)=P_{t}
$$

\subsection{Entrepreneurs (Borrowers)}

The activity of the second set of agents, the entrepreneurs, is at the heart of the model. These agents are risk neutral. They purchase unfinished capital from the capital producers at the price $Q_{t}$ and transform it into finished capital to be rented to intermediated goods producers. To finance the purchase of unfinished capital they employ internal funds but need also to acquire an external loan from a financial intermediary. The relationship with the lender is subject to an agency cost problem, which forces the entrepreneur to pay a premium on the loan. We will elaborate below on this point.

We assume that the entrepreneurs are finitely lived (with $\theta$ being the probability of dying in each period ) and risk neutral. This assumption assures that entrepreneurial consumption occurs to such an extent that self-financing never occurs and borrowing constraints on loans are always binding. Resorting to the law of large numbers and to the characteristics of the loan contract will allow a convenient aggregation for these agents' decisions. As consumers, the entrepreneurs act as simple finitely lived agents who in every period consume a constant share of their wealth.

Let's define by $Z_{t}$ the nominal rental rate of capital. The nominal income from holding one unit of finished capital is composed of the rental rate plus the re-sell price of capital (net of depreciation and physical adjustment costs):

$$
\mathcal{Y}_{t}^{k} \equiv Z_{t}+Q_{t}\left((1-\delta)-\phi^{\prime}\left(\frac{I_{t}}{K_{t}}\right) \frac{I_{t}}{K_{t}}+\phi\left(\frac{I_{t}}{K_{t}}\right)\right)
$$

Hence the return to entrepreneurs from holding a unit of capital between $t$ and $t+1$ amounts to: 


$$
\left(1+R_{t+1}^{k}\right) \equiv \frac{\mathcal{Y}_{t+1}^{k}}{Q_{t}}
$$

\subsection{The Loan Contract Between the Borrower and the Financial Intermediary}

At the end of period $t$ a continuum of entrepreneurs (indexed by $j$ ) need to finance the purchase of new capital $K_{t+1}^{j}$ that will be used for production in period $t+1$. In order to acquire a loan the entrepreneurs have to engage in a financial contract before the realization of an idiosyncratic shock $\omega(j)$ (with a payoff paid after the realization of the same shock). The idiosyncratic shock has positive support, is independently distributed (across entrepreneurs and time) with a uniform distribution, $F(\omega)$, with unitary mean, and density function $f(\omega)$. The return of the entrepreneurial investment is observable to the outsider only through the payment of a monitoring cost $\mu \mathcal{Y}_{t+1}^{k} K_{t+1}^{j}$, where $\mu$ is the fraction of lender's output lost in monitoring costs. Hence this cost is proportional to the expected return on capital purchased at the end of period $t$.

Before entering the loan contract agreement each entrepreneur owns end-of-period internal funds for a nominal amount $N W_{t+1}^{j}$ and seeks to finance the purchase of new capital $Q_{t} K_{t+1}^{j}$. We assume that the required funds for investment exceed internal funds. Hence in every period each entrepreneur seeks for a loan (in nominal terms):

$$
L_{t+1}^{j}=Q_{t} K_{t+1}^{j}-N W_{t+1}^{j} \geq 0
$$

The financial contract assumes the form of an optimal debt contract à la Gale and Hellwig (1985). When the idiosyncratic shock to capital investment is above the cut-off value which determines the default states the entrepreneurs repay a fixed amount $\left(1+R_{t+1}^{L}\right)$. On the contrary, in the default states, the bank monitors the investment activity and repossesses the assets of the firm.

Default occurs when the return from the investment activity $\mathcal{Y}_{t+1}^{k} K_{t+1}^{j}$ falls short of the amount that needs to be repaid $\left(1+R_{t+1}^{L}\right) L_{t+1}^{j}$. Hence the default space is implicitly defined as that range for $\omega$ such that :

$$
\omega_{t+1}^{j}<\varpi_{t+1}^{j} \equiv \frac{\left(1+R_{t+1}^{L}\right) L_{t+1}^{j}}{\mathcal{Y}_{t+1}^{k} K_{t+1}^{j}}
$$

where $\varpi_{t+1}^{j}$ is a cut-off value for the idiosyncratic productivity shock, which is determined endogenously in the general equilibrium ${ }^{9}$.

The timing of events can be summarized as follows

- End of period $t$.

\footnotetext{
${ }^{9}$ The fact that default is an equilibrium phenomenon is a crucial difference between the endogenous agency cost models (as the ones employed here) and the credit-cycle models a la Kyotaki and Moore (1997).
} 
1. Entrepreneur $j$ holds nominal net worth $N W_{t+1}^{j}$, acquires loan $L_{t+1}^{j}$ to purchase new capital $K_{t+1}^{j}$ which will be available to rental market and production in period $t+1$.

2. Idiosyncratic shock $\omega_{t+1}^{j}$ to the newly purchased capital realizes.

- Period $t+1$.

1. Aggregate shocks to productivity and government consumption realize.

2. Entrepreneur supplies capital services to rental market.

3. Entrepreneur pays off loan services to the lender.

4. Current net worth realizes.

\subsection{Optimal Contract}

Let's define by $\Gamma\left(\varpi^{j}\right)$ and $1-\Gamma\left(\varpi^{j}\right)$ the fractions of net capital output received by the lender and the entrepreneur respectively. Hence we have:

$$
\Gamma\left(\varpi_{t+1}^{j}\right) \equiv \int_{0}^{\varpi_{t+1}^{j}} \omega_{t+1}^{j} f(\omega) d \omega+\varpi_{t+1}^{j} \int_{\varpi_{t+1}}^{\infty} f(\omega) d \omega
$$

Expected monitoring costs are defined as:

$$
\mu M\left(\varpi_{t+1}^{j}\right) \equiv \int_{0}^{\varpi_{t+1}^{j}} \omega_{t+1}^{j} f(\omega) d \omega
$$

Hence the net share accruing to the lender is $\Gamma\left(\varpi_{t+1}^{j}\right)-\mu M\left(\varpi_{t+1}^{j}\right)$. The return paid on deposits is given by the safe rate $\left(1+R_{t}^{n}\right)$, which as such corresponds, for the lender, to the opportunity cost of financing capital.

The participation constraint for the lender states that the expected return from the lending activity should not fall short of the opportunity cost of finance:

$$
\mathcal{Y}_{t+1}^{k} K_{t+1}^{j}\left(\Gamma\left(\varpi_{t+1}^{j}\right)-\mu M\left(\varpi_{t+1}^{j}\right)\right) \geq\left(1+R_{t}^{n}\right)\left(Q_{t} K_{t+1}^{j}-N W_{t+1}^{j}\right)
$$

The contract specifies a pair $\left\{\varpi_{t+1}^{j}, L_{t+1}^{j}\right\}$ which solves the following maximization problem:

$$
\operatorname{Max}\left(1-\Gamma\left(\varpi_{t+1}^{j}\right)\right) \mathcal{Y}_{t+1}^{k} K_{t+1}^{j}
$$

subject to the participation constraint (11). Let $\chi_{t}$ be the lagrange multiplier on (11). First order conditions with respect to $\varpi_{t+1}^{j}$ and $K_{t+1}^{j}$ read: 


$$
\begin{gathered}
\Gamma^{\prime}\left(\varpi_{t+1}^{j}\right)=\chi_{t}\left(\Gamma^{\prime}\left(\varpi_{t+1}^{j}\right)-\mu M^{\prime}\left(\varpi_{t+1}^{j}\right)\right) \\
\frac{\left(1+R_{t+1}^{k}\right)}{\left(1+R_{t}^{n}\right)}\left(\left(1-\Gamma\left(\varpi_{t+1}^{j}\right)\right)+\chi_{t}\left(\Gamma\left(\varpi_{t+1}^{j}\right)-\mu M\left(\varpi_{t+1}^{j}\right)\right)\right)=\chi_{t}
\end{gathered}
$$

In addition, with $\chi_{t}>0$, (11) must hold with equality.

\subsubsection{Counter-cyclical Premium on External Finance}

Combining (13) and (14) yields a linear relationship between capital demand and net worth. This linearity of the optimal contract allows easy aggregation. This yields the following relation between the expected return on capital and the safe return paid on deposits:

$$
E_{t}\left\{1+R_{t+1}^{k}\right\}=\rho\left(\varpi_{t+1}\right)\left(1+R_{t}^{n}\right)
$$

where

$$
\rho\left(\varpi_{t+1}\right)=\left[\frac{\left(1-\Gamma\left(\varpi_{t+1}\right)\right)\left(\Gamma^{\prime}\left(\varpi_{t+1}\right)-\mu M^{\prime}\left(\varpi_{t+1}\right)\right)}{\Gamma^{\prime}\left(\varpi_{t+1}\right)}+\left(\Gamma\left(\varpi_{t+1}\right)-\mu M\left(\varpi_{t+1}\right)\right)\right]^{-1}
$$

with $\rho^{\prime}(\varpi)>0$.

Let's define $\psi_{t} \equiv E_{t}\left\{\frac{\left(1+R_{t+1}^{k}\right)}{\left(1+R_{t}^{n}\right)}\right\}$ as the premium on external finance. This ratio captures the difference between the cost of finance reflecting the existence of monitoring costs, and the safe interest rate (which per se reflects the opportunity cost for the lender). By combining (11) with (15) one can write a relationship between capital expenditure $Q_{t} K_{t+1}$ and net worth $N W_{t+1}$ whose proportionality factor depends endogenously on $\psi_{t}$ :

$$
Q_{t} K_{t+1}=\left(\frac{1}{1-\psi_{t}\left(\Gamma\left(\varpi_{t+1}\right)-\mu M\left(\varpi_{t+1}\right)\right)}\right) N W_{t+1}
$$

Equation (16) is a key relationship in this context, for it explicitly shows the link between capital expenditure and entrepreneurs' financial conditions (summarized by aggregate net worth). One can view (16) as a demand equation, in which the demand of capital depends inversely on the price and positively on the aggregate financial conditions.

On the other hand, one can write the finance premium $\psi_{t}$ as:

$$
\psi_{t}=h\left(\varpi_{t+1}\right)\left(1-\frac{N W_{t+1}}{Q_{t} K_{t+1}}\right)
$$


where $h\left(\varpi_{t+1}\right) \equiv\left[\Gamma\left(\varpi_{t+1}\right)-\mu M\left(\varpi_{t+1}\right)\right]^{-1}$. One can easily show that $h^{\prime}(\bullet)>0$. This expression suggests that the external finance premium is an equilibrium inverse function of the aggregate financial conditions in the economy, expressed by the (inverse) leverage ratio $\frac{N W_{t+1}}{Q_{t} K_{t+1}}$.

The countercyclical behavior of the finance premium and the related acceleration phenomenon stems from two effects. Consider a productivity boom, which raises the current and expected future marginal product of capital. This raises the asset price $Q_{t}$. Notice that this link would disappear in the absence of adjustment costs on capital, which are the only source of endogeneity of asset prices. Since capital is basically fixed in the short run, a rise in the asset price competes with a rise in net worth in driving the behavior of borrowing needs (see equation (9)). Holding net worth constant, the rise in the asset price drives borrowing needs upward. However, the rise in the asset price stimulates net worth more than proportionally, thereby driving borrowing needs downward, and generating a countercyclical response of the finance premium via two effects in equation (17): a fall in the default threshold $\varpi_{t+1}$ (and therefore a fall in $h\left(\varpi_{t+1}\right)$ ) and a rise in the ratio $\frac{N W_{t+1}}{Q_{t} K_{t+1}}$.

\subsubsection{Net Worth Accumulation}

Aggregate net worth at the end of period $t$ is proportional to the realization of capital income:

$$
N W_{t+1}=\theta\left(1-\Gamma\left(\varpi_{t+1}\right)\right) \mathcal{Y}_{t}^{k} K_{t}
$$

By lagging (11) one period and combining with (18) one can describe the evolution between period $t$ and $t+1$ of aggregate nominal net worth as

$$
\begin{aligned}
N W_{t+1}= & \theta\left(1+R_{t}^{k}\right) Q_{t-1} K_{t} \\
& -\theta\left(\left(1+R_{t}^{n}\right)+\frac{\mu M\left(\varpi_{t}\right)\left(1+R_{t}^{k}\right) Q_{t-1} K_{t}}{Q_{t-1} K_{t}-N W_{t}}\right)\left(Q_{t-1} K_{t}-N W_{t}\right)
\end{aligned}
$$

Equation (19) illustrates the ambiguous role that movements in $R_{t}^{k}$ exert on the accumulation of net worth. On the one hand, a rise in $R_{t}^{k}$ signals a higher return to any owned unit of capital in period $\mathrm{t}$, and therefore tends to rise net worth. On the other hand, in equilibrium, a higher $R_{t}^{k}$ also corresponds (ceteris paribus) to a higher cost of external finance, and therefore contributes to the risk premium factor $\frac{\mu M\left(\varpi_{t}\right)\left(1+R_{t}^{k}\right) Q_{t-1} K_{t}}{Q_{t-1} K_{t}-N W_{t}}$ that augments the nominal safe return on deposits $\left(1+R_{t}^{n}\right)$, thereby reducing net worth. In equilibrium, capital accumulation must be such that the rate of return on capital equates the marginal cost of finance.

Finally, entrepreneurs' consumption is given by a constant share of capital income:

$$
C_{t}^{e}=(1-\theta)\left(1-\Gamma\left(\varpi_{t+1}\right)\right) \mathcal{Y}_{t}^{k} K_{t}
$$




\subsection{Production and Pricing of Intermediate Goods}

Each domestic household owns an equal share of the intermediate-goods producing firms. ${ }^{10}$ Each firm assembles labor (supplied by the workers) and (finished) entrepreneurial capital to operate a constant return to scale production function for the variety $i$ of the intermediate good:

$$
Y_{t}(i)=A_{t} F\left(N_{t}(i), K_{t}(i)\right)
$$

where $A_{t}$ is a productivity shifter common to all entrepreneurs. Each firm $i$ has monopolistic power in the production of its own variety and therefore has leverage in setting the price. In so doing it faces a quadratic cost equal to $\frac{\omega_{p}}{2}\left(\frac{P_{t}(i)}{P_{t-1}(i)}-\pi\right)^{2}$, where $\pi$ is the steady-state inflation rate and where the parameter $\omega_{p}$ measures the degree of nominal price rigidity. ${ }^{11}$ The higher $\omega_{p}$ the more sluggish is the adjustment of nominal prices. In the particular case of $\omega_{p}=0$, prices are flexible.

The problem of each domestic monopolistic firm is the one of choosing the sequence $\left\{K_{t}(i), N_{t}(i), P_{t}(i)\right\}_{t=0}^{\infty}$ in order to maximize expected discounted real profits $\Theta_{t} \equiv P_{t}(i) Y_{t}(i)-\left(W_{t} N_{t}(i)+Z_{t} K_{t}(i)\right)-$ $\frac{\omega_{p}}{2}\left(\frac{P_{t}(i)}{P_{t-1}(i)}-\pi\right)^{2}:$

$$
E_{0}\left\{\sum_{t=0}^{\infty} \beta^{t} U_{c, t} \frac{\Theta_{t}}{P_{t}}\right\}
$$

subject to the constraint $A_{t} F(.) \geq Y_{t}(i)$. Let's denote by $\left\{m c_{t}\right\}_{t=0}^{\infty}$ the sequence of lagrange multipliers on the above demand constraint, and by $\widetilde{p}_{t} \equiv \frac{P_{t}(i)}{P_{t}}$ the relative price of variety $i$. The first order conditions of the above problem read:

$$
\begin{gathered}
\frac{W_{t}}{P_{t}}=m c_{t} A_{t} F_{n, t} \\
\frac{Z_{t}}{P_{t}}=m c_{t} A_{t} F_{k, t} \\
0=Y_{t} \widetilde{p}_{t}^{-\vartheta}\left((1-\vartheta)+\vartheta m c_{t}\right)-\omega_{p}\left(\pi_{t} \frac{\widetilde{p}_{t}}{\widetilde{p}_{t-1}}-\pi\right) \frac{\pi_{t}}{\widetilde{p}_{t-1}} \\
+\omega_{p}\left(\pi_{t+1} \frac{\widetilde{p}_{t+1}}{\widetilde{p}_{t}}-\pi\right) \pi_{t+1} \frac{\widetilde{p}_{t+1}}{\widetilde{p}_{t}^{2}}
\end{gathered}
$$

\footnotetext{
${ }^{10}$ An alternative ownership structure could be explored, in which the entrepreneurs directly own the shares of the intermediate goods firms that employ capital in production. In this case monopolistic profits would be part of capital income $\mathcal{Y}_{t}^{k}$, as in Cook (2002).

${ }^{11}$ Recall that, in our framework, $\pi>0$. An alternative formulation may feature adjustment costs penalizing the deviation of the rate of change of prices from the past inflation rate $\pi_{t-1}$. However, Schmitt-Grohe and Uribe (2004b) show that the latter formulation (similar to the one employed in Christiano et al. (2003)) biases the optimal policy towards generating an inflation volatility significantly different from zero.
} 
where $\pi_{t} \equiv \frac{P_{t}}{P_{t-1}}$ is the gross inflation rate, and where we have suppressed the superscript i, since all firms employ an identical capital/labor ratio in equilibrium. Notice that the lagrange multiplier $m c_{t}$ plays the role of the real marginal cost of production. In a symmetric equilibrium it must hold that $\widetilde{p}_{t}=1$. This implies that $(25)$ can be written in the form of a forward-looking Phillips curve relationship:

$$
\begin{aligned}
U_{c, t}\left(\pi_{t}-\pi\right) \pi_{t}= & \beta E_{t}\left\{U_{c, t+1}\left(\pi_{t+1}-\pi\right) \pi_{t+1}\right\} \\
& +U_{c, t} A_{t} F(.) \frac{\vartheta}{\omega_{p}}\left(m c_{t}-\frac{\vartheta-1}{\vartheta}\right)
\end{aligned}
$$

\subsection{Final Good Sector}

The aggregate final good $Y$ is produced by perfectly competitive firms. It requires assembling a continuum of intermediate goods, indexed by $i$, via the aggregate production function:

$$
Y_{t} \equiv\left(\int_{0}^{1} Y_{t}(i)^{\frac{\vartheta-1}{\vartheta}} d i\right)^{\frac{\vartheta}{\vartheta-1}}
$$

Maximization of profits yields typical demand functions:

$$
Y_{t}(i)=\left(\frac{P_{t}(i)}{P_{t}}\right)^{-\vartheta} Y_{t}
$$

for all $i$, where $P_{t} \equiv\left(\int_{0}^{1} P_{t}(i)^{1-\vartheta} d i\right)^{\frac{1}{1-\vartheta}}$ is the price index consistent with the final good producers earning zero profits.

\subsubsection{Final Goods Market Clearing}

Equilibrium in the final good market requires that the production of the final good be allocated to private consumption by households and entrepreneurs, investment, public spending, and to resource costs that originate from the adjustment of prices as well as from the lender's monitoring of the investment activity:

$$
Y_{t}=C_{t}+C_{t}^{e}+I_{t}+G_{t}+\frac{\omega_{p}}{2}\left(\pi_{t}-\pi\right)^{2}+\mu M\left(\varpi_{t}\right) y_{t}^{k} K_{t}
$$

where $y_{t}^{k} \equiv \frac{\mathcal{Y}_{t}^{k}}{P_{t}}$. Here $G_{t}$ is government consumption of the final good which evolves exogenously and is assumed to be financed by means of lump sum taxes. 


\subsection{Monetary Policy}

We assume that monetary policy is conducted by means of an interest rate reaction function, constrained to be linear in the logs of the relevant arguments:

$$
\begin{aligned}
\ln \left(\frac{1+R_{t}^{n}}{1+R^{n}}\right)= & \left(1-\phi_{r}\right)\left(\phi_{\pi} \ln \left(\frac{\pi_{t}}{\bar{\pi}}\right)+\phi_{y} \ln \left(\frac{Y_{t}}{\bar{Y}}\right)+\phi_{q} \ln q_{t}\right) \\
& +\phi_{r} \ln \left(\frac{1+R_{t-1}^{n}}{1+R^{n}}\right)
\end{aligned}
$$

Notice that this general specification allows for a reaction of the monetary policy instrument to deviations of the real price of capital $q_{t} \equiv \frac{Q_{t}}{P_{t}}$ from its efficient value 1 .

Our approach consists in assuming that the monetary authority can fully commit to the specification in (30) and then finding the policy specification $\left\{\phi_{\pi}, \phi_{y}, \phi_{q}, \phi_{r}\right\}$ that maximizes household's welfare. In addition, we will be evaluating the relative welfare of a series of alternative simple Taylor-type rules which impose alternative ad-hoc restrictions on (30).

\section{Calibration and Solution Strategy}

We employ a period utility function $U\left(C_{t}, N_{t}\right)=\log \left(C_{t}\right)+\nu \log \left(1-N_{t}\right)$, with $\nu$ chosen in such a way to generate a steady state level of employment $N=0.3$. We set the discount factor $\beta=0.99$, so that the annual real interest rate is equal to $4 \%$. The share of capital in the production function $\alpha$ is 0.3 , the quarterly depreciation rate $\delta$ is 0.025 , the elasticity of substitution between varieties is 6 , which yields a steady state mark-up of $20 \%$. The elasticity of the price of capital with respect to investment output ratio $\varphi$ is 0.5 .

In line with the evidence reported in Carlstrom and Fuerst (1997) we set $\mu$ equal to 0.25. We calibrate the steady state to imply an annual (average) external finance premium $\psi=1.02$ (two hundred basis points), and to generate an average bankruptcy rate of three percent $(F(\bar{\omega})=0.03)$.

Log-productivity evolves as follows :

$$
\ln \left(A_{t}\right)=\rho_{a} \ln A_{t-1}+\varepsilon_{t}^{a}
$$

where the steady-state value $A$ is normalized to unity and where $\varepsilon_{t}^{a}$ is an iid shock with standard deviation $\sigma_{a}$. In line with the real business cycle literature (see King and Rebelo, 1999). We set $\rho_{a}=0.95$ and $\sigma_{a}=0.0056$. Log-government consumption is assumed to evolve according to the following process:

$$
\ln \left(\frac{G_{t}}{G}\right)=\rho_{g} \ln \left(\frac{G_{t-1}}{G}\right)+\varepsilon_{t}^{g}
$$


where $G$ is the steady-state share of government consumption (set in such a way that $\frac{G}{Y}=0.25$ ) and $\varepsilon_{t}^{g}$ is an iid shock with standard deviation $\sigma_{g}$. We follow the empirical evidence for the United States in Perotti (2004) and set $\sigma_{g}=0.008$ and $\rho_{g}=0.9$.

Credit Frictions and Higher Order Approximation We solve the model by computing a second order approximation of the policy functions around the non-stochastic steady state (with positive average inflation, monopolistic distortions and monitoring costs). In the Appendix we describe in more detail the form of the recursive equilibrium conditions.

Notice that an alternative interpretation of equation (17) may be in terms of a borrowing constraint:

$$
L_{t+1}=\left[\left(\frac{1}{1-\psi_{t}\left(\Gamma\left(\varpi_{t+1}\right)-\mu M\left(\varpi_{t+1}\right)\right)}\right)-1\right] N W_{t+1}
$$

This constraint has two features: (i) it is derived as equilibrium condition of an optimal contract; (ii) it holds with equality in all periods, due to the endogenous behavior of the finance premium $\psi$ and of the cut-off value $\varpi$. This is a fundamental difference between this framework and the credit cycle model of Kyotaki and Moore (1997), and it bears important consequences for the application of our solution method. In the model of Kyotaki and Moore, in fact, the borrowing constraint is a typical collateral constraint on quantities. Namely, the borrower's debt cannot exceed a certain fraction of the collateral, with this fraction being exogenously determined. Noticeably, and unlike equation (16) or (17), the same constraint is imposed to be binding in all periods. This friction would be highly problematic in a context like ours in which stochastic uncertainty plays a key role in the evaluation of the welfare performance of monetary policy. ${ }^{12}$ In fact, in that case, nothing may rule out that in the presence of a favorable spell of positive shocks to entrepreneurs' net worth a buffer-stock behavior may dominate a behavior consistent with the collateral constraint holding with equality. Hence accounting for the role of uncertainty in models with exogenous collateral constraints on quantities would most likely require solution algorithms dealing with occasionally binding constraints (see for instance Christiano and Fisher (2000)).

\section{Steady-State and Equilibrium Dynamics}

In Appendix $A$ we describe the strategy employed for the computation of the steady state. Figure 1 shows the solution of the steady state of the KA model for a number of selected variables.

[Figure 1 about here]

\footnotetext{
${ }^{12}$ For instance, and among other things, this is a fundamental difference between our framework and the one employed in Iacoviello (2004), who analyzes the effects of monetary policy in terms of an inflation-output volatility frontier in the context of a log-linearized model a la Kyotaki and Moore.
} 
The value of each variable is plotted against a choice of the monitoring cost parameter $\mu$, i.e., the fraction of net output that the lender needs to employ for monitoring activity. It should be noticed that a situation in which this fraction approaches zero corresponds to one in which credit market imperfections are absent. The figure is representative of the distortion on the steady-state level of capital and output induced by the existence of agency costs. Hence we see that larger values of $\mu$ correspond to a larger steady-state external finance premium $\psi$. This raises the default threshold $\bar{\omega}$, which in turn raises the entrepreneurs' bankruptcy rate $F(\bar{\omega})$. As a consequence, larger monitoring costs depress the average level of capital stock and output.

\subsection{Responses to a Productivity Shock: Counter-cyclical Premium and Accel- eration}

Figure 2 reports, for the KA model, impulse responses of selected variables to a one percent positive rise in total factor productivity for alternative values of $\mu$ (solid line $\mu=0$, dashed line $\mu=0.25$ ). For illustrative purposes, we temporarily assume that monetary policy is conducted by means of a special case of (30) corresponding to a simple Taylor rule:

$$
\ln \left(\frac{1+R_{t}^{n}}{1+R^{n}}\right)=1.5 \ln \left(\frac{\pi_{t}}{\bar{\pi}}\right)
$$

[Figure 2 about here]

All numbers are in percent deviations from steady-state values. The figure is representative of the acceleration effect induced by the presence of credit frictions. Hence we see that a current rise in productivity (which is accompanied also by a rise in expected future productivity given the persistence in the innovation) triggers a rise in the asset price and investment. Crucially, net worth responds quickly in the short run, driving the default threshold down (as well as the bankruptcy rate). Notice that the quick response of the net worth depends on the "credit cycle" effect induced by the movement in the asset price. Given that capital is fixed in the short-run, the rise in the asset price induces a more than proportional rise in net worth, which drives borrowing requirements down. As a result, the cost of external finance falls on impact, reinforcing the effect on net worth and in turn on the asset price and investment. As it is clear, the countercyclical response of the finance premium is stronger the larger the size of the monitoring imperfections.

What is important for our purposes is that, conditional on a positive rise in productivity, asset price and financial markup (the external finance premium) are negatively correlated. This is the central feature of the acceleration model. Notice that this feature depends crucially on borrowing frictions applying to the financing of the entire stock of capital. This is the factor that makes 
the demand for borrowing procyclical. In fact, in equation (9), net worth $N W_{t}$ rises more than proportionally relative to the term $Q_{t} K_{t+1}$, thereby lowering the demand for borrowing

Notice also that credit frictions work in the direction of dampening the response of inflation to the rise in technology. This is due to the fact that fostered capital accumulation with accelerated investment triggers, for any given level of employment, a rise in the real marginal cost, which tends to dampen the countercyclical response of inflation to technology shocks that is typical of sticky price models with frictionless credit markets. ${ }^{13}$ As further explored below, this relative "inflationary" effect of financial frictions is crucial in determining the optimal response of monetary policy in this context.

\section{$5 \quad$ Welfare Evaluation}

The critical feature of our analysis consists in the assessment of alternative interest rate rules based on the evaluation of household's welfare. Some observations on the computation of welfare in this context are in order. First, one cannot safely rely on standard first order approximation methods to compare the relative welfare associated to each monetary policy arrangement. In fact, in an economy like ours, in which distortions exert an effect both in the short-run and in the steady state, stochastic volatility affects both first and second moments of those variables that are critical for welfare. Since in a first order approximation of the model's solution the expected value of a variable coincides with its non-stochastic steady state, the effects of volatility on the variables' mean values is by construction neglected. Hence policy arrangements can be correctly ranked only by resorting to a higher order approximation of the policy functions. ${ }^{14}$

This last observation also suggests that our welfare metric needs to be correctly chosen. In particular, one needs to focus on the conditional expected discounted utility of the representative agent. This is necessary exactly to take into account of transitional effects from the deterministic to the different stochastic steady states respectively implied by each alternative policy rule.

A third observation concerns our representation of policy. It is clear that the optimal choice of $\left\{\phi_{\pi}, \phi_{y}, \phi_{q}, \phi_{r}\right\}$ delivers the welfare-maximizing policy within the constrained class of linear interest rate rules specified in (30). Alternatively, it would only be the solution to the full Ramsey planner problem (under commitment) to yield a representation of the globally optimal allocation. However, the specification and solution of the Ramsey problem in the presence, as here, of a relatively large number of state variables involves a series of non trivial technical problems. In addition, and more

\footnotetext{
${ }^{13}$ For instance, see Gali et al. (2003), Ireland (2003).

${ }^{14}$ See Kim and Kim (2003) for an analysis of the inaccuracy of welfare calculations based on log-linear approximations in dynamic open economies. See Kim et al. (2003) and Schmitt-Grohe and Uribe (2004a) for a more general discussion.
} 
importantly, the formulation of policy in terms optimal (simple) interest rate rules has attracted considerable attention for its ability of striking a sound balance between the rigor of a choicetheoretic evaluation of policy (as opposed to ad-hoc loss functions) and the requirement that the same normative formulation of policy be easily implementable.

Finally it is important to recall that our framework features heterogeneity of consumers. However, entrepreneurs are risk-neutral agents. This implies that their mean level of consumption is unaffected by the sources of stochastic volatility. Hence, alternative interest rate rules not only will imply the same (deterministic) steady-state level of all variables, but they will also imply the same stochastic mean consumption for entrepreneurs. As a matter of fact, and as already noticed by Chari, Kehoe and McGrattan (2004), a model economy which features the type of credit frictions embedded here can be easily reduced (via an equivalence argument) to a simple representative agent economy with a variable tax on investment (which, in the context of the KA model, would correspond to the external finance premium). This implies that a measure accounting for both workers' and entrepreneurs' welfare, need simply to be amended by adding the (conditional) mean level of entrepreneurial consumption. Hence the overall welfare measure of our economy is simply the convexified function ${ }^{15}$ :

$$
\mathcal{W}_{0}=\xi\left\{E_{0} \sum_{t=0}^{\infty} \beta^{t} U\left((1+\Omega) C_{t}, N_{t}\right)\right\}+(1-\xi)\left\{\frac{\beta}{1-\beta} C_{t}^{e}\right\}
$$

where $\xi$ is the weight assigned to workers' utility. However, as emphasized in Bernanke, Gertler and Gilchrist (1998), the fraction of entrepreneurial consumption over aggregate consumption can be reasonably assumed to be negligible. Under the assumption that the entrepreneurial share of consumption is negligible (i.e., $\xi \rightarrow 1$ ) we can rely on a synthetic welfare measure which is given by the fraction $\Omega$ of household's consumption that would be needed to equate conditional welfare $\mathcal{W}_{0}$ under a generic interest rate policy to the level of welfare $\widetilde{\mathcal{W}}_{0}$ implied by the optimal rule. Hence $\Omega$ should satisfy the following equation:

$$
\mathcal{W}_{0, \Omega}=E_{0}\left\{\sum_{t=0}^{\infty} \beta^{t} U\left((1+\Omega) C_{t}, N_{t}\right)\right\}=\widetilde{\mathcal{W}}_{0}
$$

Under our specification of utility one can solve for $\Omega$ and obtain:

$$
\Omega=\exp \left\{\left(\widetilde{\mathcal{W}}_{0}-\mathcal{W}_{0}\right)(1-\beta)\right\}-1
$$

\footnotetext{
${ }^{15}$ Convexification procedures have been commonly used also in the optimal taxation literature which studies the optimal allocation of taxes across heterogenous agents. See Judd (1998).
} 


\subsection{Responding to Asset Prices}

We first simulate the KA economy under the two sources of aggregate uncertainty, productivity and government consumption shocks. We conduct two types of experiments. First, we compute welfare under different (ad hoc) specifications of the monetary policy rule. The rules are the following: (i) Strict Inflation Targeting; (ii) Asset Price Targeting; (iii) Simple Taylor rule, with $\phi_{\pi}=1.5$ and $\phi_{y}=\phi_{q}=\phi_{r}=0$; (iv) Taylor rule + asset prices, with $\phi_{\pi}=1.5, \phi_{q}=0.5, \phi_{y}=0$; (v) Taylor rule + Finance Premium, with $\phi_{\pi}=1.5, \phi_{\psi}=0.5, \phi_{y}=0$ and where $\phi_{\psi}$ is a coefficient involving a response to the finance premium rather than the asset price (see below for further comments). Furthermore rules (iii)-(v) are evaluated with and without interest rate smoothing $\left(\phi_{r}=0\right.$ and $\phi_{r}=0.9$ respectively). ${ }^{16}$ Second, we search in the grid of parameters $\left\{\phi_{\pi}, \phi_{y}, \phi_{q}, \phi_{r}\right\}$ for the rule which delivers the highest level of welfare, which we define as the optimal policy rule. ${ }^{17}$

The choice of evaluating strict asset price stabilization (rule (ii)) is motivated by the recent debate on the potential role of asset price targeting as accelerator of the Great Depression. ${ }^{18}$ Hence it seems of particular interest to evaluate the relative welfare performance of asset price versus nominal price stabilization.

Table 1 summarizes our main findings. The values of the policy parameters that are found to maximize conditional welfare, as well as the welfare loss $\Omega$ (relative to the optimal policy) of alternative simple rules are reported.

[Table 1 about here]

Several aspects are worth emphasizing. First, among the simple rules analyzed above strict stabilization of inflation is the optimal rule. Second, strict asset price stabilization is clearly welfare detrimental, and features the worst performance in the family of rules considered. Third, positive interest rate smoothing is part of the optimal policy rule. In general, it also substantially improves the welfare performance of all the simple rules considered here.

To further investigate whether the response to asset prices in a Taylor rule signals an independent welfare effect, Figures 3 and 4 report the effects on conditional welfare of varying both the

\footnotetext{
${ }^{16}$ For the sake of simplicity we do not report the results in the case of a positive response to output. In fact, and across rules, a reaction to output is strongly welfare detrimental. This result is consistent with the one obtained by Schmitt-Grohe and Uribe (2004) in a model economy with capital accumulation, no adjustment cost and frictionless credit markets. This welfare loss is mainly due to the fact that we pick the "wrong" target. Since optimal monetary policy conduct aims at reducing inefficient output variations, the right target is likely to be the deviation of output from potential rather than output itself. More specifically, in our case potential output would correspond to the constrained Pareto optimum, namely the solution achieved by the Ramsey planner.

${ }^{17}$ We search over the following ranges: $[0,4]$ for $\phi_{\pi},[0,2]$ for $\phi_{q},[0,1]$ for $\phi_{y}$. We then compare rules with interest rate smoothing $\left(\phi_{r}=0.9\right)$ to rules without smoothing $\left(\phi_{r}=0\right)$. We judged as admissible a combination of policy parameters that delivered a unique rational expectations equilibrium.

${ }^{18}$ See for instance Bernanke (2002).
} 
inflation and the asset price coefficients on the monetary policy rule, respectively without and with interest rate smoothing.

[Figure 3 and 4 about here ]

The main message that emerges in both pictures is that if there exists a positive (although minor) effect on welfare from responding to asset prices this happens to be the case only for low values of the response to inflation (and in particular in the presence of interest rate smoothing). In general, optimal policy prescribes a strong anti-inflationary stance. Thus, for low values of $\phi_{\pi}$, responding to asset prices is a way to implement a "leaning against the wind" policy that allows to complement the only partial inflation targeting response. When monetary policy turns strongly anti-inflationary, the scope for responding to asset prices disappears. As we see, at high levels of $\phi_{\pi}$ the welfare function becomes completely flat in $\phi_{\pi}$.

\subsubsection{Targeting the Financial Markup}

Our results so far point to a minimal role for asset prices in an optimal setting of interest rate rules. A rule featuring a very strong reaction to inflation seems to replicate closely the welfare performance of the (constrained) optimal rule.

However, there is room to argue that a monetary authority concerned with maximizing the welfare of the representative consumer may wish to engineer a response to indicators that more directly signal the cyclical evolution of financial frictions in the economy. In this respect, it seems natural to explore the effects of rules which include the external finance premium directly as an independent argument. Hence we search for the optimal combination of $\left\{\phi_{\pi}, \phi_{y}, \phi_{\psi}, \phi_{r}\right\}$ in a rule of the type:

$$
\begin{aligned}
\ln \left(\frac{1+R_{t}^{n}}{1+R^{n}}\right)= & \left(1-\phi_{r}\right)\left(\phi_{\pi} \ln \left(\frac{\pi_{t}}{\bar{\pi}}\right)+\phi_{y} \ln \left(\frac{Y_{t}}{\bar{Y}}\right)+\phi_{\psi} \ln \left(\frac{\psi_{t}}{\psi}\right)\right) \\
& +\phi_{r} \ln \left(\frac{1+R_{t-1}^{n}}{1+R^{n}}\right)
\end{aligned}
$$

where $\psi>1$ is the steady-state level of the finance premium.

Figures 5 and 6 report the effects on conditional welfare of varying both the inflation and the finance premium coefficients on the monetary policy rule specified as in (34), respectively without and with interest rate smoothing. 
[Figure 5 and 6 about here]

Notice that in this case we let the premium parameter $\phi_{\psi}$ vary in the range $[-1,1]$. The message emerging from Table 1 and Figures 5 and 6 is twofold. On the one hand, responding to the finance premium in addition to inflation seems to improve the welfare performance of simple Taylor rules better than responding to asset prices. This is especially evident from inspecting Figures 6 . Thus we see that, although minor, welfare gains from responding to the finance premium persist even when the inflation coefficient is high and in the order of $\phi_{\pi}=3$. On the other hand, as a general principle, the results in Table 1 confirm that a strict stabilization of inflation continues to dominate a hybrid rule featuring a response to both inflation and finance premium.

\subsubsection{Why Price Stability?}

The general message of the KA model is that, regardless of whether the monetary authority responds to movements in asset prices or in the external finance premium (in addition to inflation), optimal policy does not deviate from the strict inflation targeting prescription. The intuition for this result lies in a typical public finance argument. In a nutshell, there is no inherent trade-off for the monetary authority in managing the two distortions that characterize the equilibrium dynamics in this context: sticky goods prices, which generate fluctuations in price markups, and credit frictions, which generate acceleration in asset prices and fluctuations in the financial markup (finance premium). To gain an intuition, consider a scenario with technology shocks, which are the chief source of variability in this context. A positive rise in productivity causes a fall in the finance premium and an (over)acceleration in investment. Ceteris paribus, this calls for a rise in real interest rates to stabilize the finance premium. On the other hand, and relative to scenario in which credit frictions are absent, the rise in productivity also causes a rise in inflation (despite inflation generally falling below steady state, see Figure 2). Hence, at the margin, monetary authority's preferred response is a rise in real interest rates to contract demand and minimize fluctuations in price markups. As emphasized earlier, the key point is that financial frictions operate in the direction of dampening the (negative) response of inflation to productivity shocks relative to a situation in which the same frictions are absent.

\section{The Investment-Propagation Model}

At the heart of the KA model illustrated above lies a typical financial acceleration effect. Its dynamics are mainly driven by a countercyclical behavior of the financial markup and by a negative correlation between the latter and the asset price. However, these elements need not necessarily be a feature of any model embedding credit market frictions. Below we illustrate a theoretical 
framework, still based on the presence of endogenous agency costs, in which these central mechanics are reversed. In this model, asset price movements are genuinely a symptom of financial frictions, in the sense that the relative price of investment goods is determined by the interaction of demand and supply in a lending market characterized by a moral hazard problem. Hence, here, reacting to asset prices may bear a more solid public finance argument for monetary policy, for its cyclicality is strictly motivated by the presence of financial imperfections (as opposed to the KA model in which a necessary condition for the endogeneity of asset prices is the presence of adjustment costs on capital). In this environment, that we henceforth label Investment-Propagation (IP) model, asset prices and finance premium (financial markup) are positively correlated (while the opposite is true in the KA model). Hence it is of particular interest to understand whether the strong antiinflationary prescription that emerges from the KA model survives in a credit frictions environment in which the financial markup is procyclical.

The IP model presented below is a sticky-price monetary extension of Carlstrom and Fuerst (1997). Below, we illustrate only the essential features that differentiate it from the KA model.

\subsection{Households}

There is continuum of households in this economy with measure 1, with utility function as in (1). Households derive income from renting labor and capital to intermediate goods firms (whose prices are sticky), and from receiving profits of the same monopolistic firms. They use their income to purchase two types of goods: consumption (final) goods $C_{t}$ and investment goods $I_{t}$ from the entrepreneurs. Investment goods are originally consumption goods transformed via the entrepreneurial activity to be described later. The household's sequence of budget constraints reads:

$$
P_{t} C_{t}+Q_{t} I_{t}+D_{t+1} \leq\left(1+R_{t}^{n}\right) D_{t}+W_{t} N_{t}+Z_{t} K_{t}^{h}+\Upsilon_{t}+T_{t}
$$

where $K_{t}^{h}$ is capital held by households. The purchase of investment goods contributes to capital accumulation as follows ${ }^{19}$ :

$$
K_{t+1}^{h}=(1-\delta) K_{t}^{h}+I_{t}
$$

Let's define by $q_{t} \equiv \frac{Q_{t}}{P_{t}}$ the relative price of investment goods and $z_{t} \equiv \frac{Z_{t}}{P_{t}}$ the real rental rate of capital. Efficiency conditions require:

\footnotetext{
${ }^{19}$ Notice that we do not model adjustment costs on capital. In fact, this version of the model can be thought of as one in which adjustment costs on capital (and asset prices as a result) are endogenous.
} 


$$
\begin{gathered}
U_{c, t}=\beta\left(1+R_{t}^{n}\right) E_{t}\left\{U_{c, t+1} \frac{P_{t}}{P_{t+1}}\right\} \\
U_{c, t} \frac{W_{t}}{P_{t}}=-U_{n, t} \\
U_{c, t}=\beta E_{t}\left\{U_{c, t+1}\left(\frac{q_{t+1}(1-\delta)+z_{t+1}}{q_{t}}\right)\right\}
\end{gathered}
$$

Equations (37) and (38) are standard conditions on bonds investment and labor supply. Equation (39) is an intertemporal investment demand condition. The essence of the IP model consists in building a theory for the endogenous cyclical behavior of $q_{t}$ based on capital market frictions, going beyond the mere existence of adjustment costs on capital.

\subsection{Entrepreneurs}

The second set of agents in the economy, of measure $\eta$, are the entrepreneurs. Their activity consists in purchasing consumption goods and transform them into investment goods via an instantaneous risky technology. To purchase final goods they employ internal resources, but need also to acquire a financial loan. As in the KA model, the structure of the financial contract requires the entrepreneurs to be risk neutral agents. We follow Carlstrom and Fuerst (1997) and assume the following utility function:

$$
E_{0}\left\{\sum_{t=0}^{\infty}(\beta \gamma)^{t} C_{t}^{e}\right\}, 0<\gamma<1
$$

Notice that the entrepreneurs have a lower discount rate than households, an assumption which insures that the entrepreneurs never hold enough wealth to overcome the financing constraints. ${ }^{20}$ Entrepreneurs earn income from renting the capital stock to intermediate firms, with $K_{t}^{e}$ being entrepreneurial capital. Hence their nominal net worth can be written: ${ }^{21}$

$$
N W_{t}=\left[Z_{t}+Q_{t}(1-\delta)\right] K_{t}^{e}
$$

Each entrepreneur purchases final goods for the nominal amount $P_{t} I_{t}$ and invest in a risky technology that produces $\omega_{t} I_{t}$ units of capital goods within the same period. ${ }^{22} \mathrm{He} /$ she must borrow a nominal amount $P_{t} I_{t}-N W_{t}$, and agrees to repay $\left(1+R_{t}^{n}\right)$ per nominal unit borrowed. Hence, for

\footnotetext{
${ }^{20}$ We employ this strategy here to maintain similarity with the framework in Carlstrom and Fuerst (1997). The alternative assumption, employed in the KA model illustrated above, simply requires that the entrepreneurs be rule-of-thumb consumers who survive with probability $\theta$ and consume their end-of-period capital income.

${ }^{21}$ We abstract here from modelling entrpreneurial labor supply.

${ }^{22} \mathrm{As}$ in the KA model loan contracts are just one-periods contracts.
} 
a non-defaulting entrepreneur the realization of $\omega_{t}$ must be such that $\omega_{t}>\bar{\omega}_{t}$, where the latter is the default threshold which, in analogy with equation (10), must satisfy:

$$
\bar{\omega}_{t}=\frac{\left(1+R_{t}^{n}\right)\left(P_{t} I_{t}-N W_{t}\right)}{P_{t} I_{t}}
$$

The problem of a non-defaulting entrepreneur is to maximize (40) subject to the sequence of budget constraints:

$$
Q_{t} K_{t+1}^{e}+P_{t} C_{t}^{e}=Q_{t} I_{t}\left(\omega_{t}-\bar{\omega}_{t}\right)
$$

This intertemporal problem must satisfy the Euler equation:

$$
1=\beta \gamma E_{t}\left\{\left(\frac{q_{t+1}(1-\delta)+z_{t+1}}{q_{t}}\right) \psi_{t+1}^{I}\right\}
$$

where

$$
\psi_{t}^{I} \equiv\left(1+R_{t}^{n}\right) q_{t}
$$

is the premium on external funds. Below we show how this premium is related to the aggregate financial conditions and to the default threshold via the specification of the optimal contract on investment.

\subsection{Financial Contract on Investment}

The structure of the contract is similar to the one in the KA model. The crucial difference is that, for each entrepreneur, the contract specifies an investment amount $I_{t}$ along with a threshold value $\varpi_{t}$ that solve the following maximization problem $^{23}$ :

$$
\operatorname{Max}\left(1-\Gamma\left(\varpi_{t}\right)\right) Q_{t} I_{t}
$$

subject to the lender's participation constraint:

$$
Q_{t} I_{t}\left[\Gamma\left(\varpi_{t}\right)-\mu M\left(\varpi_{t}\right)\right] \geq L_{t}
$$

Efficiency requires that (45) holds with equality. It is show that the solution to the problem above, taking advantage of linear aggregation as in the KA model, implies the following two first order conditions:

\footnotetext{
${ }^{23}$ We omit for simplicity to specify the contract in idiosyncratic terms $j$. We already know from the KA model how aggregation is easily implemented in this context.
} 


$$
\begin{gathered}
I_{t}=\frac{n w_{t}}{1-q_{t}\left[\Gamma\left(\varpi_{t}\right)-\mu M\left(\varpi_{t}\right)\right]} \\
q_{t}=\rho\left(\varpi_{t}\right)
\end{gathered}
$$

where $n w_{t} \equiv \frac{N W_{t}}{P_{t}}$, and $\rho\left(\varpi_{t}\right)$ coincides with (15). Equation (46) is a crucial condition in this context. It expresses the supply of capital as a function of the relative price of the investment goods $q_{t}$ and of the (aggregate) financial conditions proxied by the level of net worth $n w_{t}$. Notice that in the space $\left(q_{t}, I_{t}\right)$ movements in net worth have the effect of shifting the investment supply schedule, in turn affecting the relative price of investment goods. This is the feature that genuinely signals the presence of monitoring imperfections in the lender-borrower relationship.

By combining (46) with (47) and (41) it is easy to show that the finance premium can be written:

$$
\psi_{t}^{I}=\frac{\varpi_{t}}{\left[\Gamma\left(\varpi_{t}\right)-\mu M\left(\varpi_{t}\right)\right]} \equiv \psi^{I}\left(\varpi_{t}\right)
$$

Notice that, since monitoring costs increase with $\varpi_{t}$, it must be that $\psi^{I^{\prime}}(\bullet)>0$. In other words, and intuitively, a rise in the default threshold triggers a rise in the external finance premium.

\subsubsection{Calibration}

To calibrate and solve the IP model we follow the same strategy employed for the KA model. A relevant parameter that characterizes the IP model uniquely is the entrepreneurs' discount rate $\gamma$, which we calibrate in order to obtain a steady-state finance premium $\psi^{I}=1.02$. Notice that in the steady-state of the IP model the presence of non-zero monitoring $\operatorname{costs}(\mu>0)$ implies that relative price of capital exceeds one $(q>1)$.

\subsection{Dynamics in the IP model: Pro-Cyclical Finance Premium}

To illustrate the dynamics of the IP model Figure 7 reports impulse responses of selected variables to a positive productivity shock. The solid and the dashed line signal the response conditional on a value of $\mu=0$ and $\mu=0.25$ respectively. All numbers are in percent deviations from steadystate values. This illustrative exercise is again conducted under the temporary assumption that monetary policy is conducted via a simple Taylor rule as in (32).

[Figure 7 about here] 
The critical element to notice is that in this case the rise in investment coupled with the rise in the asset price is paralleled by a slow response in net worth. In fact, in the short-run, net worth is mostly composed of entrepreneurial capital, and its dynamic is sluggish. The net result is an initial rise in borrowing needs (i.e., $q_{t} I_{t}$ rises relatively more than $n w_{t}$ ) and in the marginal cost of investment. In turn, this generates a rise in the default threshold $\varpi_{t}$. For the finance premium is an increasing function of $\varpi_{t}$, the result is a rise in the external finance premium. However, over time, net worth accumulates, and its response shifts the investment supply schedule outwards and to such an extent that the asset price starts to revert downward. It is this delayed response of net worth that induces a subsequent boost to investment, thereby generating the observed hump-shaped dynamics.

Interestingly, and somewhat in contrast with the KA model, the reactivity of net worth is inversely proportional to the degree of financial frictions summarized by $\mu$. Hence, in this framework, financial frictions are synonymous with persistence rather than acceleration. Even more subtly, and as emphasized in Carlstrom and Fuerst (1998), acceleration and persistence seems to be related by a trade-off. It is important to notice that what critically distinguishes the IP model from the KA model is the comovement between $q_{t}$ and the finance premium $\psi_{t}$. Since both are positively correlated with $\varpi_{t}$, the cyclical response of the default threshold is critical in driving their mutual correlation. In turn, what drives the movement of the default threshold is the demand for borrowing, which responds procyclically in this context. As a result, the default threshold rises and the finance premium is procyclical and positively correlated with the asset price.

\subsection{Welfare and Robustness of Price Stability}

Table 1 (bottom panel) reports the welfare evaluation of the same simple rules analyzed in the upper panel in the context of the KA model. Hence we see that also in the context of the IP model inflation targeting emerges as the optimal rule. This is confirmed by the grid-search analysis presented in Figure 8 and 9.

[Figure 8 and 9 about here]

Even more strikingly, and already at low levels of the inflation response $\phi_{\pi}$ (consistent with a baseline Taylor rule), responding to asset prices is welfare detrimental. Notice that, for the sake of exposition, we do not report the results of rules that respond to the finance premium. In fact, in the IP model, and due to the strict correlation between asset price and finance premium, a rule that features a response to the finance premium performs virtually the same as a rule that implies a response to the asset price. 
We believe that the robustness of inflation targeting as optimal policy within the IP model is a particularly interesting result. In fact, a priori, and due to the procyclicality of the finance premium, this model would have suggested a potential tension between the goals of financial and price markup stabilization. Our reasoning proceeds as follows. Recall that in response to a productivity shock, and as illustrated in Figure 7, the IP model generates a procyclical response of the financial markup. Ceteris paribus, and in the short run, this implies that investment falls below its level that would prevail in the absence of credit frictions. In other words, this model generates a procyclical tax on investment. Hence, along this margin, the desired policy response would require a fall in the real interest rate. The crucial issue is whether this goal is consistent with the one of price markup stabilization. Hence we see from Figure 7 that, on impact, inflation falls below steady state (dashed line). More importantly, it also lies persistently below the level that would prevail in the absence of credit frictions (solid line). Hence, like in the KA model and relative to a benchmark in which credit markets are frictionless, credit frictions operate here in the direction of dampening the response of inflation to technology shocks. In turn, this calls for lowering the real interest rate below its natural level. This fall in the real rate can accommodate both the financial markup stabilization motive and the price markup stabilization motive. Interestingly, while neither the KA model nor the IP model seem to generate a policy trade-off, the required behavior of the real interest rate (relative to the credit-frictionless level) is different in the two cases.

\section{Conclusions}

We have analyzed optimal interest rules in the context of two general equilibrium models featuring sticky prices, endogenous agency costs and asset prices. In the first model, credit frictions apply to the financing of physical capital, while in the second model to the financing of the investment flow. Although the two frameworks deliver opposite predictions concerning the cyclical movement of the "financial markup", we find that strict inflation stabilization is a robust optimal monetary policy prescription. The intuition lies in the fact that while the two models generate quite different dynamics of inflation and investment, in both of them credit frictions work in the direction of dampening the cyclical behavior of inflation relative to a hypothetical scenario in which the same frictions are removed. If, in response to a positive productivity shock, credit frictions generate acceleration and over-investment (as in the KA model) we find that inflation remains above its level in the absence of credit frictions. On the other hand, if credit frictions generate hump-shaped dynamics and keep investment below its frictionless level in the short-run (as in the IP model), we observe that inflation remains below its level in the absence of credit frictions. In both cases, a manipulation of the real interest rate is consistent with the two public finance motives that drive the 
welfare analysis in this context: stabilization of the price markup and stabilization of the financial markup.

An important caveat of our analysis concerns the characteristics of the contracting problem featured in our economy. To formalize the relationship between lender and borrower we employ a costly state verification contract in which the cost of loans is indexed to future expected inflation. This implies that the real version of the external finance premium is independent of future expected inflation. Hence the monetary authority endowed with a single instrument - i.e., the nominal interest rate - cannot have a direct leverage on the financial distortion. We conjecture that if non-indexed contracts were in place, which implies a direct dependence of the external finance premium on expected inflation, the monetary authority would have a stronger incentive to inflate the economy. Surprise inflation would indeed increase the value of nominal net worth, thereby reducing the expost value of real debt and the cost of the loan. This argument, which is in line with the Fisherian theory of debt deflation, might call for sizeable deviations of optimal monetary policy from the price stability target. We are currently investigating these issues in ongoing parallel work. 


\section{A Equilibrium}

KA Model Let's define $q_{t} \equiv \frac{Q_{t}}{P_{t}}, y_{t}^{k} \equiv \frac{\mathcal{Y}_{t}^{k}}{P_{t}}, n w_{t} \equiv \frac{N W_{t}}{P_{t}}, z_{t} \equiv \frac{Z_{t}}{P_{t}}$. For given processes $\left\{A_{t}, G_{t}\right\}_{t=0}^{\infty}$ a recursive (imperfectly) competitive equilibrium in the KA model is a sequence of allocations for $C_{t},\left(1+R_{t}^{n}\right), \pi_{t}, m c_{t}, N_{t}, q_{t}, I_{t},\left(1+R_{t+1}^{k}\right), z_{t}, C_{t}^{e}, \varpi_{t}, y_{t}^{k}, n w_{t}, K_{t+1}$ which solves the following system of equations:

$$
\begin{aligned}
& U_{c, t}=\beta\left(1+R_{t}^{n}\right) E_{t}\left\{\frac{U_{c, t+1}}{\pi_{t+1}}\right\} \\
& m c_{t} A_{t} F_{n, t}=\frac{-U_{n, t}}{U_{c, t}} \\
& m c_{t} A_{t} F_{k, t}=z_{t} \\
& q_{t}=\left[1-\phi_{k}\left(\frac{I_{t}}{K_{t}}-\delta\right)\right]^{-1} \\
& \frac{\left(1+R_{t+1}^{k}\right)}{\pi_{t+1}}=\frac{E_{t}\left\{y_{t+1}^{k}\right\}}{q_{t}} \\
& y_{t+1}^{k} K_{t+1}\left(\Gamma\left(\varpi_{t+1}\right)-\mu M\left(\varpi_{t+1}\right)\right)=\left(1+R_{t}^{n}\right)\left(q_{t} K_{t+1}-n w_{t+1}\right) \\
& U_{c, t}\left(\frac{\pi_{t}}{\pi}-1\right) \frac{\pi_{t}}{\pi}=\beta E_{t}\left\{U_{c, t+1}\left(\frac{\pi_{t+1}}{\pi}-1\right) \frac{\pi_{t+1}}{\pi}\right\}+\frac{U_{c, t} A_{t} F\left(K_{t}, N_{t}\right) \vartheta}{\omega_{p}}\left(m c_{t}-\frac{\vartheta-1}{\vartheta}\right) \\
& n w_{t+1}=\theta\left(1-\Gamma\left(\varpi_{t}\right)\right) y_{t}^{k} K_{t} \\
& A_{t} F(.)=C_{t}+C_{t}^{e}+I_{t}+\frac{\omega_{p}}{2}\left(\frac{\pi_{t}}{\pi}-1\right)^{2}+\mu M\left(\varpi_{t}\right) y_{t}^{k} K_{t}+G_{t} \\
& C_{t}^{e}=(1-\theta) \Gamma\left(\varpi_{t}\right) y_{t}^{k} K_{t} \\
& K_{t+1}=(1-\delta) K_{t}+I_{t}-\frac{\phi_{k}}{2}\left(\frac{I_{t}}{K_{t}}-\delta\right)^{2} K_{t} \\
& \ln \left(\frac{1+R_{t}^{n}}{1+R^{n}}\right)=\left(1-\phi_{r}\right)\left(\phi_{\pi} \ln \left(\frac{\pi_{t}}{\bar{\pi}}\right)+\phi_{y} \ln \left(\frac{Y_{t}}{\bar{Y}}\right)+\phi_{q} \ln q_{t}\right)+\phi_{r} \ln \left(\frac{1+R_{t-1}^{n}}{1+R^{n}}\right) \\
& y_{t}^{k}=z_{t}+q_{t}\left(1-\delta+\frac{\phi_{k}}{2}\left(\frac{I_{t}}{K_{t}}-\delta\right)^{2}-\phi_{k}\left(\frac{I_{t}}{K_{t}}-\delta\right) \frac{I_{t}}{K_{t}}\right)
\end{aligned}
$$


IP model For given processes $\left\{A_{t}, G_{t}\right\}_{t=0}^{\infty}$, a recursive (imperfectly) competitive equilibrium in the IP model is a sequence of allocations for $C_{t},\left(1+R_{t}^{n}\right), \pi_{t}, m c_{t}, N_{t}, q_{t}, I_{t},\left(1+R_{t+1}^{k}\right), z_{t}, C_{t}^{e}$, $\varpi_{t}, y_{t}^{k}, \psi_{t}^{I}, n w_{t+1}, K_{t+1}^{h}, K_{t+1}^{e}$ which solves the following system of equations:

$$
\begin{gathered}
U_{c, t}=\beta\left(1+R_{t}^{n}\right) E_{t}\left\{\frac{y_{t+1}^{k}}{q_{t}}\right\} \\
q_{t}=\beta \gamma E_{t}\left\{y_{t+1}^{k} q_{t+1} \psi_{t+1}^{I}\right\} \\
I_{t}=\frac{n w_{t}}{\left(1-q_{t}\left(\Gamma\left(\varpi_{t}\right)-\mu M\left(\varpi_{t}\right)\right)\right)} \\
K_{t+1}^{e}=\frac{\eta n w_{t}\left(1-\Gamma\left(\varpi_{t}\right)\right)}{1-q_{t}\left(\Gamma\left(\varpi_{t}\right)-\mu M\left(\varpi_{t}\right)\right)}+\eta \frac{C_{t}^{e}}{q_{t}} \\
q_{t}^{I}=\frac{n w_{t}=\frac{y_{t}^{k} K_{t}^{e}}{\eta}}{1-q_{t}\left(\Gamma\left(\varpi_{t}\right)-\mu M\left(\varpi_{t}\right)\right)} \\
\frac{y_{t}^{k}=z_{t}+q_{t}(1-\delta)}{K_{t+1}=(1-\delta) K_{t}+\eta I_{t}\left(1-\mu M\left(\varpi_{t}\right)\right)} \\
\psi_{t} F(.)=(1-\eta) C_{t}+\eta C_{t}^{e}+\eta I_{t}+\frac{\omega_{p}}{2}\left(\frac{\pi_{t}}{\pi}-1\right)^{2}+G_{t} \\
\left.\left.\Gamma_{t+1}^{\prime}\left(\varpi_{t+1}\right)\left(\Gamma^{\prime} \varpi_{t+1}\right)-\mu \varpi_{t+1}\right)\right) \\
\left.\left.A_{t}+\Gamma\left(\varpi_{t+1}\right)-\mu M\left(\varpi_{t+1}\right)\right)\right]^{-1}
\end{gathered}
$$

To complete the description of the equilibrium one should add equations (49), (50), (54), (59).

\section{B Computation of the Deterministic Steady State in the KA model}

A critical step for the solution of the steady state in the KA model involves the computation of the cut-off value $\bar{\omega}$. We proceed as follows. From equation (18) the individual capital-net worth ratio can be written: 


$$
\frac{K}{N W}=\left[\theta(1-\Gamma(\bar{\omega})) \rho(\bar{\omega}) \beta^{-1}\right]^{-1} \equiv \kappa(\bar{\omega})
$$

where $\rho(\bar{\omega})$ follows from (15). On the other hand from (16) we have the aggregate capital-net worth ratio:

$$
\frac{K}{N W}=\{1-\rho(\bar{\omega})[\Gamma(\bar{\omega})-\mu M(\bar{\omega})]\}^{-1} \equiv \widetilde{\kappa}(\bar{\omega})
$$

Individual and aggregate capital-net worth ratios must be equalized in equilibrium. Equating (70) and (71) one obtains a non-linear equation which can be solved for the single unknown $\bar{\omega}$. This in turn yields a value for steady-state finance premium $\psi$ :

$$
\psi=\left(\frac{(1-\Gamma(\varpi))\left(\Gamma^{\prime}(\varpi)-\mu M^{\prime}(\varpi)\right)}{\Gamma^{\prime}(\varpi)}+(\Gamma(\varpi)-\mu M(\varpi))\right)^{-1}>1
$$

The real rental cost of capital $z$ is given by:

$$
z=(1+r r) \psi-1+\delta
$$

where $r r \equiv \beta^{-1}$ is the gross real rate of interest. Hence a higher finance premium, by lowering the steady-state capital stock, requires a higher rental cost of capital. In turn the output-capital ratio is given by:

$$
\left(\frac{Y}{K}\right)=\frac{\frac{\vartheta}{\vartheta-1} z}{\alpha}
$$

where $\frac{\vartheta}{\vartheta-1}$ is the steady-state markup. This in turn yields the capital-labor ratio:

$$
\left(\frac{K}{N}\right)=\left(\frac{\frac{\vartheta}{\vartheta-1} z}{\alpha}\right)^{-(1-\alpha)}
$$

The real return on capital is given by

$$
\left(1+R^{k}\right)=\pi(z+1-\delta)
$$

and nominal safe interest rate

$$
\left(1+R^{n}\right)=\frac{\pi}{\beta}
$$

where $\pi>1$ is the average gross rate of inflation.

Using (73) and the fact that, in the absence of steady-state investment adjustment costs, $\frac{I}{K}=\delta$ it is easy to compute the consumption-capital ratio as: 


$$
\frac{C}{K}=\frac{Y}{K}-\delta-\mu M(\varpi)(1+r r) \psi-\frac{C^{e}}{K}-g \frac{Y}{K}
$$

where $g \equiv \frac{G}{Y}$ and $\frac{C^{e}}{K}$ is given by $(20)$.

With preferences $U(C, N)=\log (C)+\nu \log (1+N)$ one can use (4), (73) and (77) to compute steady state labor hours as:

$$
N=\frac{\frac{(1-\alpha)}{\nu}\left(\frac{\vartheta-1}{\vartheta}\right) \frac{\frac{Y}{K}}{\frac{K}{K}}}{1+\frac{(1-\alpha)}{\nu}\left(\frac{\vartheta-1}{\vartheta}\right) \frac{\frac{Y}{K}}{\frac{K}{K}}}
$$

Computation of the remaining elements of the vector of endogenous variables follows in a straightforward manner.

\section{Solution of the Model}

The set of optimality conditions of the optimal plan can be described as follows:

$$
E_{t}\left\{\mathcal{H}\left(\Psi_{t+1}, \Psi_{t}, X_{t+1}, X_{t}\right)\right\}=0
$$

where $E_{t}$ denotes the mathematical expectations operator, conditional on information available at time t, $\Psi_{t}$ is the vector of endogenous non-predetermined variables, and $X_{t} \equiv\left[x_{1, t}, x_{2, t}\right]$ is the state vector. Here $x_{1, t}$ denotes the vector of endogenous predetermined variables, while $x_{2, t}$ is the vector of exogenous variables which follows a stochastic process:

$$
x_{2, t+1}=\digamma x_{2, t}+\bar{\eta} \bar{\xi} \varepsilon_{t+1}, \quad \varepsilon_{t} \sim \text { i.i.d.N }(0, \Sigma)
$$

where the scalars $\bar{\xi}$ and $\bar{\eta}$ are known parameters. The solution of the model is of the form (SchmittGrohe and Uribe (2004a)):

$$
\begin{gathered}
\Psi_{t}=g\left(X_{t}, \bar{\xi}\right) \\
X_{t+1}=h\left(X_{t}, \bar{\xi}\right)+\bar{\eta} \bar{\xi} \varepsilon_{t+1}
\end{gathered}
$$

Equation (81) and (82) describe the policy function and the transition function respectively. We compute a second order expansion of the functions $g\left(X_{t}, \bar{\xi}\right)$ and $h\left(X_{t}, \bar{\xi}\right)$ around the deterministic steady-state. Schmitt-Grohe and Uribe (2004a) show that, up to a second order, the coefficients of the policy functions attached to terms that are linear in the state vector $X_{t}$ are independent of the size of the volatility of the $\operatorname{shock}(\mathrm{s})$. To evaluate numerically the first and second order 
derivatives of the policy functions we employ the Matlab codes compiled by Schmitt-Grohe and Uribe, available at the website http://www.econ.duke.edu/ grohe. The second order expansion of $g$ and $h$ is required for an accurate evaluation of the value of the variable $W_{0}$ in the stochastic steady state. 


\section{References}

[1] Bernanke B., (2002), "Remarks by Governor Ben S. Bernanke Before the New York Chapter of the National Association for Business Economics", New York.

[2] Bernanke, B., M. Gertler, (2001)," Agency Costs, Net Worth and Business Fluctuations", American Economic Review, March, 14-31.

[3] Bernanke, B., M. Gertler, (2001), "Should Central Banks Respond to Movements in Asset Prices?" American Economic Review Papers and Proceedings, 91 (2), 253-257.

[4] Bernanke, B., M. Gertler and S. Gilchrist, (1999), "The Financial Accelerator in a Quantitative Business Cycle Framework", in J.B. Taylor, and M. Woodford, eds., Handbook of Macroeconomics, Amsterdam: North-Holland.

[5] Carlstrom, C. and T. Fuerst (1997), "Agency Costs, Net Worth and Business Fluctuations: A Computable General Equilibrium Analysis", American Economic Review, 87, 893-910.

[6] Carlstrom, C. and T. Fuerst (1998), "Agency Costs and Business Cycles", Economic Theory 12(3), 583-597.

[7] Cecchetti S., H. Genberg and S. Wadhwani (2002) "Asset Prices in a Flexible Inflation Targeting Framework", NBER w.p \# 8970.

[8] Chari V.V, P. Kehoe and E. McGrattan (2004), "Business Cycle Accounting", Federal Reserve Bank of Minneapolis Staff Report, 328.

[9] Christiano, L. J. and Fisher, J. D. M., (2000), "Algorithms for solving dynamic models with occasionally binding constraints," Journal of Economic Dynamics and Control, vol. 24(8), 1179-1232, 7.

[10] Christiano L., M. Eichenbaum and C. Evans (2003), "Nominal Rigidities and the Dynamic Effects of a Shock to Monetary Policy, forthcoming Journal of Political Economy.

[11] Cook, D. (2002), "Monetary Policy in Emerging Markets: Can Liability Dollarization Explain Contractionary Devaluations", forthcoming Journal of Monetary Economics.

[12] Detken, C. and F. Smets, (2004), "Asset Price Booms and Monetary Policy", ECB Working Paper No. 364

[13] Dupor, B. (2003), "Nominal Price versus Asset Price Stabilization", mimeo Ohio State University. 
[14] Erceg C., D. Henderson and A. Levin, (2000), "Optimal Monetary Policy with Staggered Wage and Price Setting", Journal of Monetary Economics, vol. 46, pp. 281-313.

[15] Gale, D. and M. Hellwig, (1985), "Incentive-Compatible Debt Contracts: The One-Period Problem", Review of Economic Studies, 52, 647-663.

[16] Galí J., Lopez_Salido D. and J. Valles (2003), "Technology Shocks and Monetary Policy: Assessing the Fed's Performance" Journal of Monetary Economics, vol 50, 723-743.

[17] Gilchrist, S. and Leahy, J. V., (2002), "Monetary policy and asset prices", Journal of Monetary Economics, vol. 49(1), pages 75-97, 1.

[18] Iacoviello, M. (2004), "'House Prices, Borrowing Constraints and Monetary policy in the Business Cycle" forthcoming American Economic Review.

[19] Ireland P.(2003), "Endogenous Money or Sticky Prices", Journal of Monetary Economics.

[20] Judd, K. (1998), "Numerical Methods in Economics", MIT Press.

[21] Khan, A., R. King and A.L. Wolman, (2003), "Optimal Monetary Policy", Review of Economic Studies, 60,4.

[22] Kim K.S., J. Kim, E. Schaumburg and C. Sims (2003), "Calculating and Using Second Order Accurate Solutions for Discrete Time Dynamic Equilibrium Models," mimeo Brandeis University.

[23] Kim K.S., J. Kim (2003), "Spurious Welfare Reversals in International Business Cycle Models", Journal of International Economics 60, pp. 471-500.

[24] King R. and S. Rebelo, (1999), "Resuscitating Real Business Cycles," in J.B. Taylor, and M. Woodford, eds., Handbook of Macroeconomics, Amsterdam: North-Holland.

[25] King, R. and A. L. Wolman, (1999), "What Should the Monetary Authority Do When Prices Are Sticky", in Taylor, J. B., ed., Monetary Policy Rules, Chicago: university of Chicago Press, 349-398.

[26] Kiyotaki, N. and J. Moore, (1997), "Credit Cycles", Journal of Political Economy, 105, April , 211-48.

[27] Kollmann R., (2003a), "Monetary Policy Rules in an Interdependent World", CEPR DP 4012 
[28] Kollmann R., (2003b), "Welfare Maximizing Fiscal and Monetary Policy Rules", mimeo University of Bonn.

[29] Kydland, F. and E. C. Prescott, (1980), "Dynamic Optimal Taxation, Rational Expectations and Optimal Control", Journal of Economic Dynamics and Control, 2:79-91.

[30] Lucas, R. E. and N. Stokey, (1983), "Optimal Fiscal and Monetary Policy in an Economy Without Capital", Journal of Monetary Economics, 12:55-93.

[31] Rotemberg, J. and M. Woodford, (1997), "An Optimization-Based Econometric Model for the Evaluation of Monetary Policy", NBER Macroeconomics Annual, 12: 297-346.

[32] Schmitt-Grohe S. and M. Uribe, (2003), "Optimal, Simple, and Implementable Monetary and Fiscal Rules", mimeo Duke University.

[33] Schmitt-Grohe S. and M. Uribe, (2004a), "Solving Dynamic General Equilibrium Models Using a Second-Order Approximation to the Policy Function", Journal of Economic Dynamics and Control 28, 645-858.

[34] Schmitt-Grohe S. and M. Uribe, (2004b), "Optimal Operational Monetary Policy in the Christiano-Eichenbaum-Evans Model of the U.S. Business Cycle ", mimeo Duke University.

[35] Woodford, Michael (2003), Interest and Prices: Foundations of a Theory of Monetary Policy, Princeton University Press.. 
Table 1. Welfare Performance of Alternative Monetary Policy Rules

\begin{tabular}{|c|c|c|}
\hline \multicolumn{3}{|c|}{ KA Model } \\
\hline Rule & \% Loss relative to Optimal & Welfare \\
\hline Strict Inflation Targeting & 0.000 & -200.796 \\
\hline Asset Price Targeting & 0.672 & -201.465 \\
\hline Taylor rule & 0.040 & -200.836 \\
\hline -with smoothing & 0.001 & -200.796 \\
\hline Taylor rule + asset price & 0.044 & -200.839 \\
\hline -with smoothing & 0.003 & -200.799 \\
\hline Taylor rule + Finance Premium & 0.017 & -200.812 \\
\hline -with smoothing & 0.001 & -200.796 \\
\hline \multicolumn{3}{|c|}{ IP Model } \\
\hline Rule & \% Loss relative to Optimal & Welfare \\
\hline Strict Inflation Targeting & 0.000 & -78.782 \\
\hline Asset Price Targeting & 1.662 & -80.430 \\
\hline Taylor rule & 0.026 & -78.808 \\
\hline -with smoothing & 0.011 & -78.793 \\
\hline Taylor rule + asset price & 0.051 & -78.833 \\
\hline -with smoothing & 0.014 & -78.796 \\
\hline Taylor rule + Finance Premium & 0.042 & -78.824 \\
\hline -with smoothing & 0.013 & -78.795 \\
\hline
\end{tabular}

Notes: Welfare Loss is the \% fraction of consumption required to equate welfare under any given policy rule to the one under the optimal policy. Welfare is calculated as conditional to the initial deterministic steady-state. 

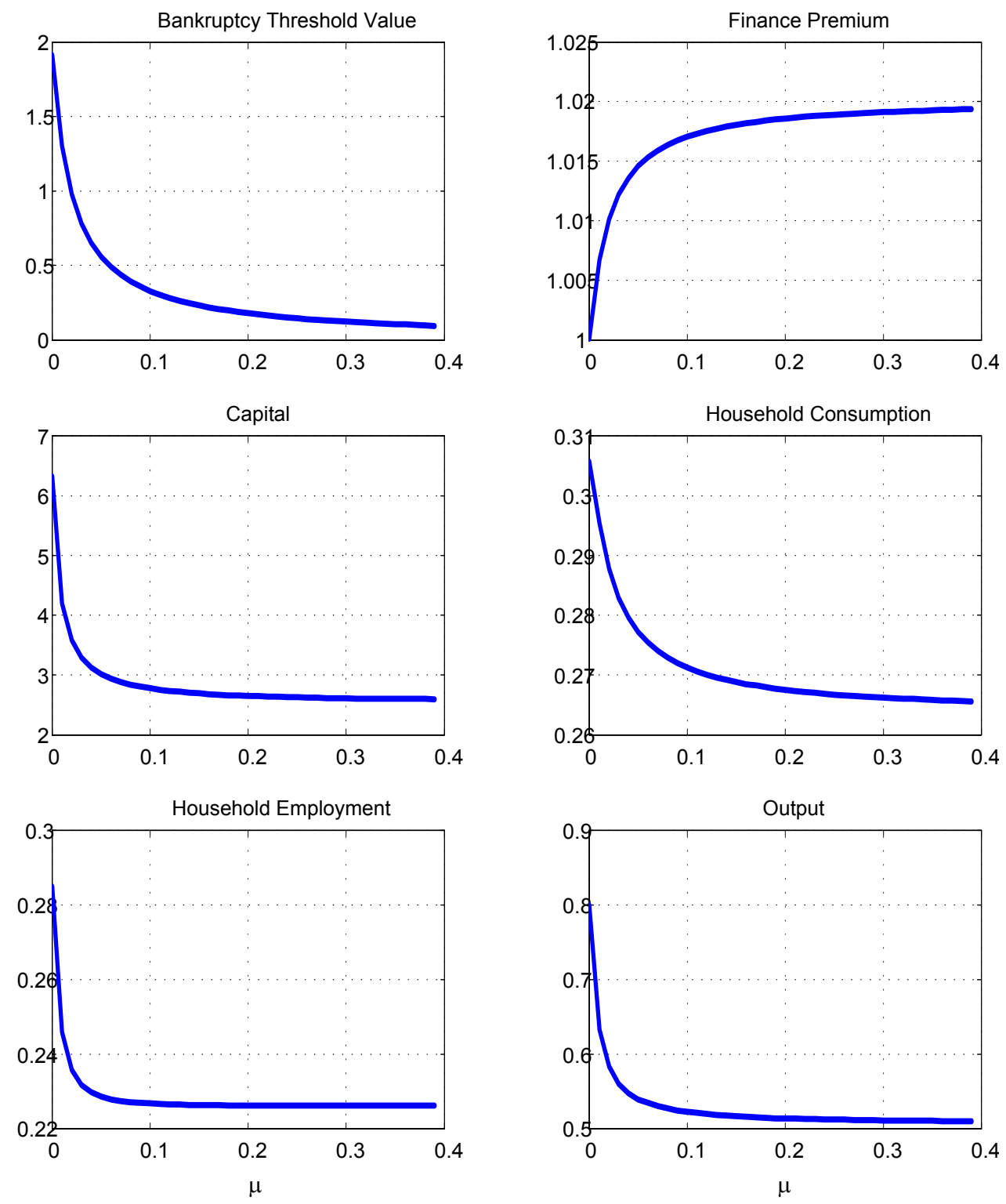

Figure 1: Steady-state Effects of Varying Monitoring Costs 

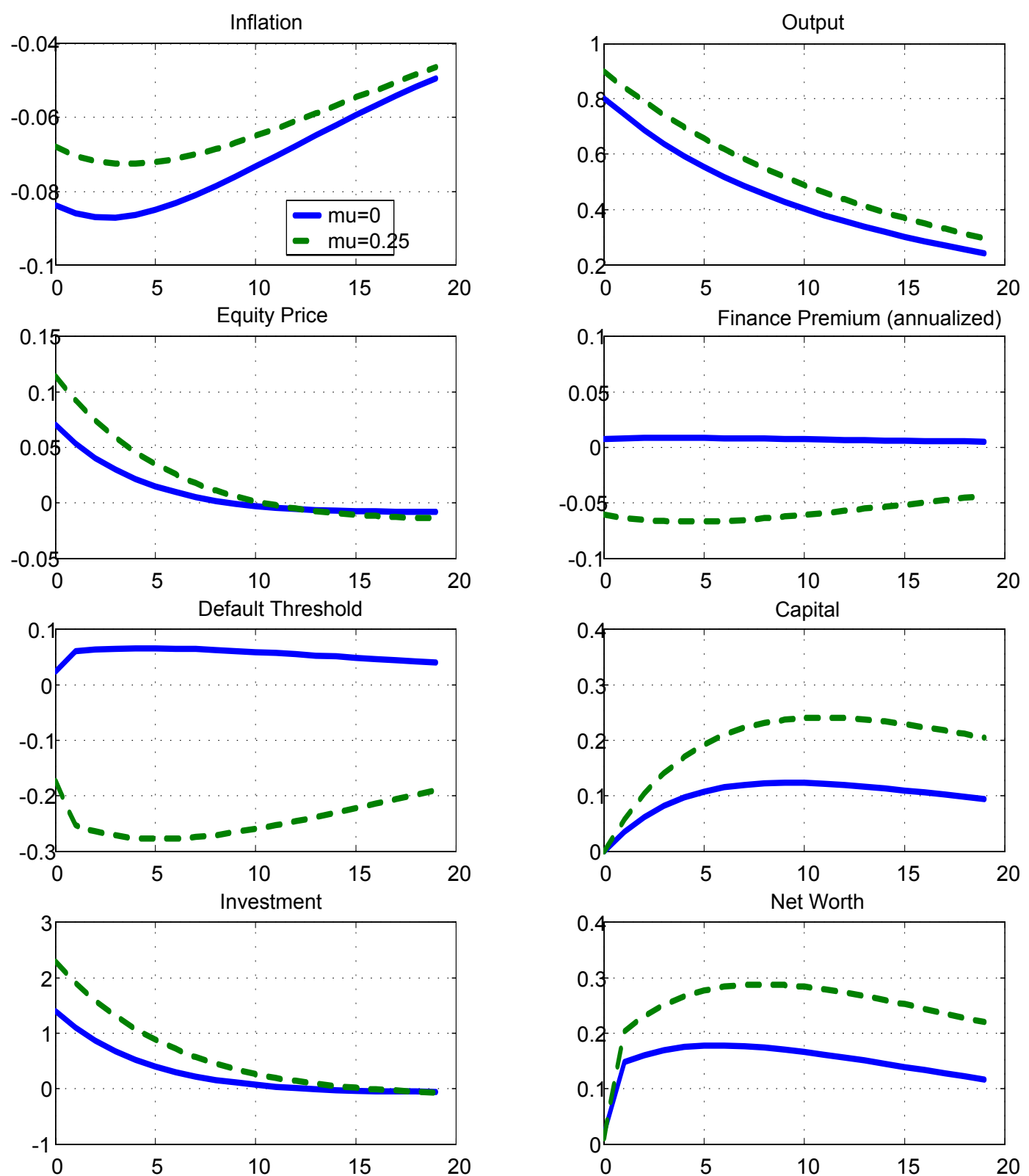

Figure 2: Impulse Responses to a Productivity Shock, without (solid) and with (dashed) credit frictions (KA model) 


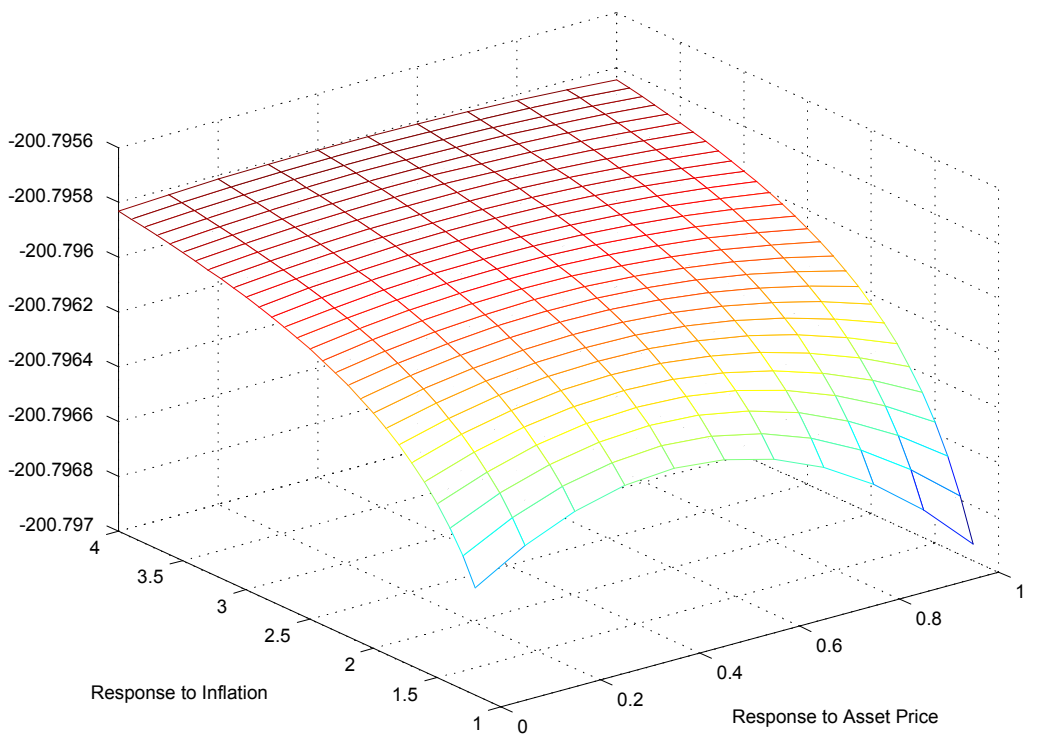

Figure 3: Effect on Welfare of Varying the Response to Inflation and Asset Price (KA model, no-smoothing)

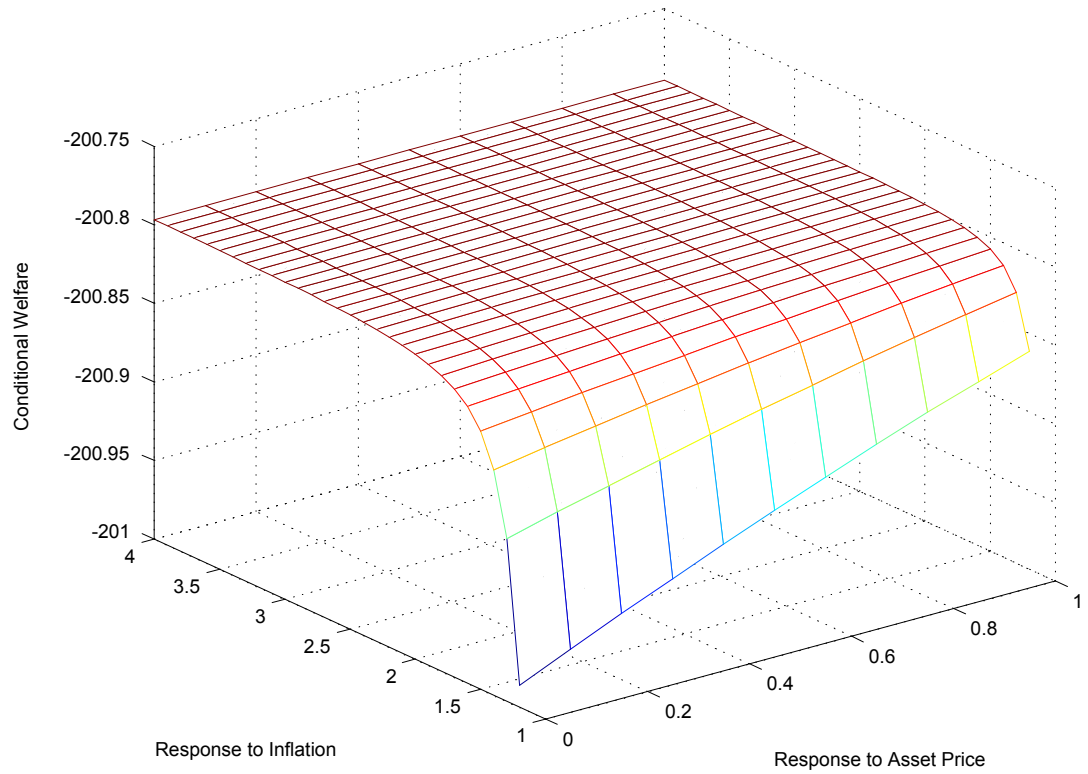

Figure 4: Effect on Welfare of Varying the Response to Inflation and Asset Price (KA model, smoothing) 


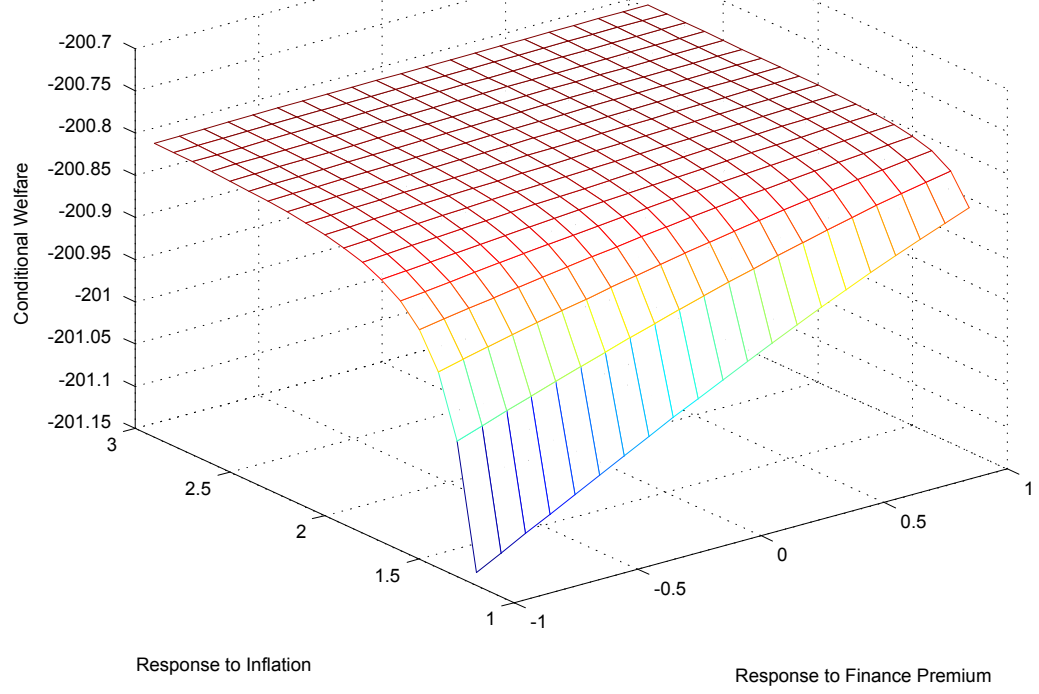

Figure 5: Effect on Welfare of Varying the Response to Inflation and Finance Premium (KA model, no-smoothing)

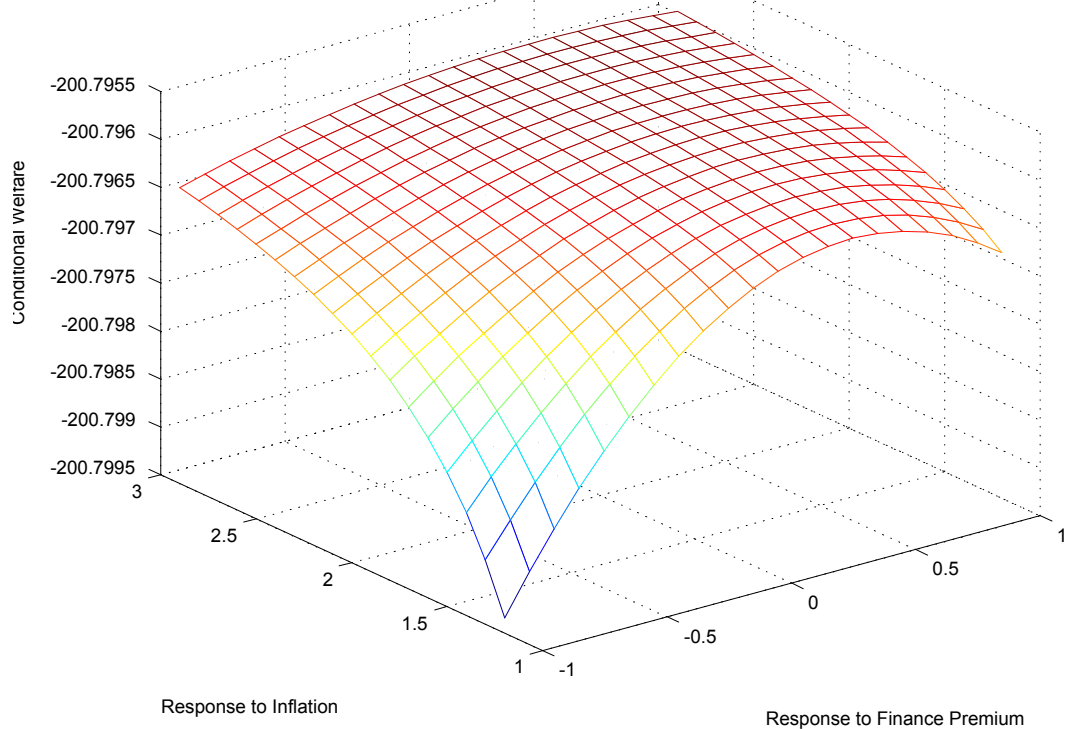

Figure 6: Effect on Welfare of Varying the Response to Inflation and Finance Premium (KA model, smoothing) 

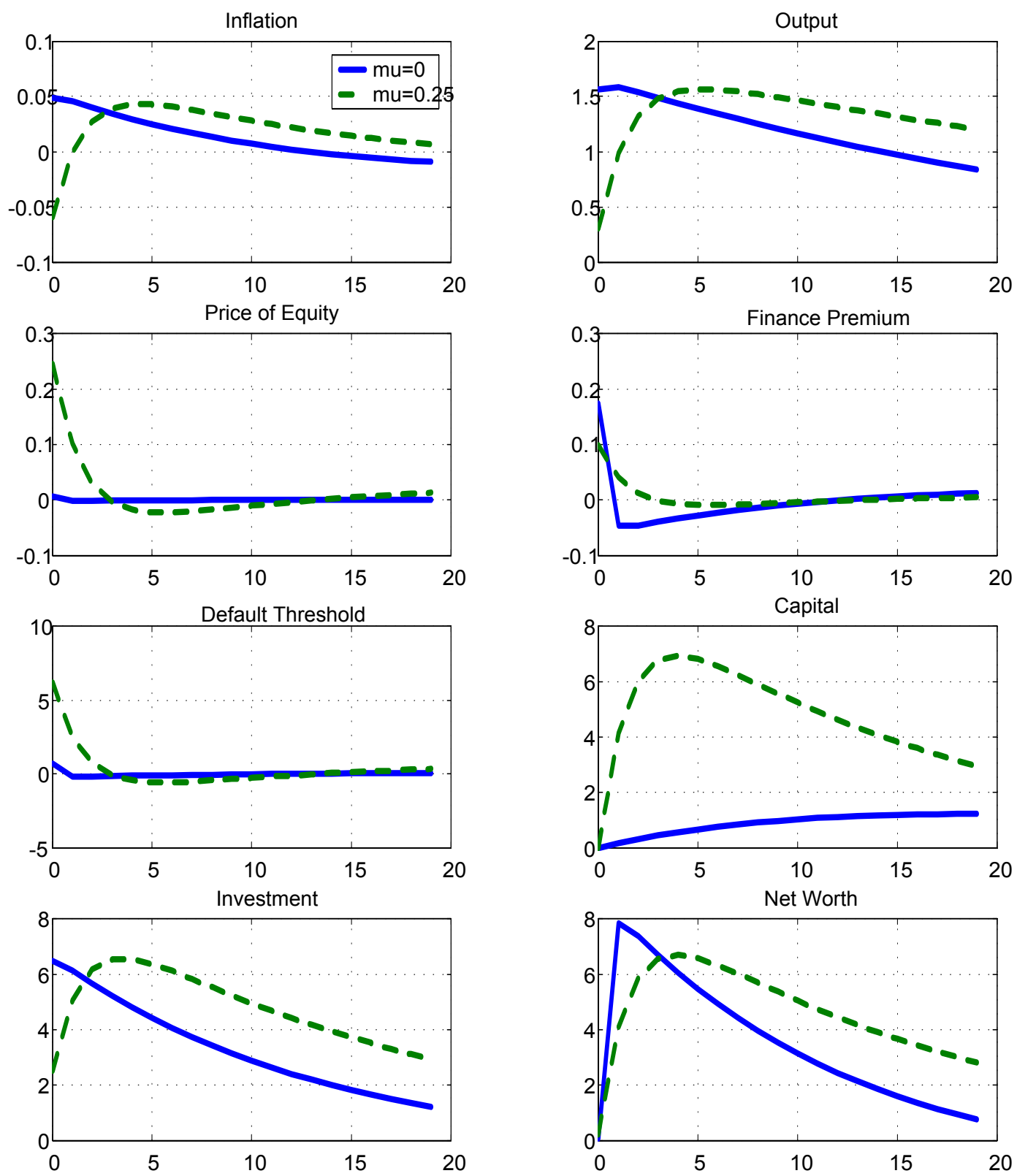

Figure 7: Impulse Responses to a Productivity Shock, without (solid) and with (dashed) credit frictions (IP model) 


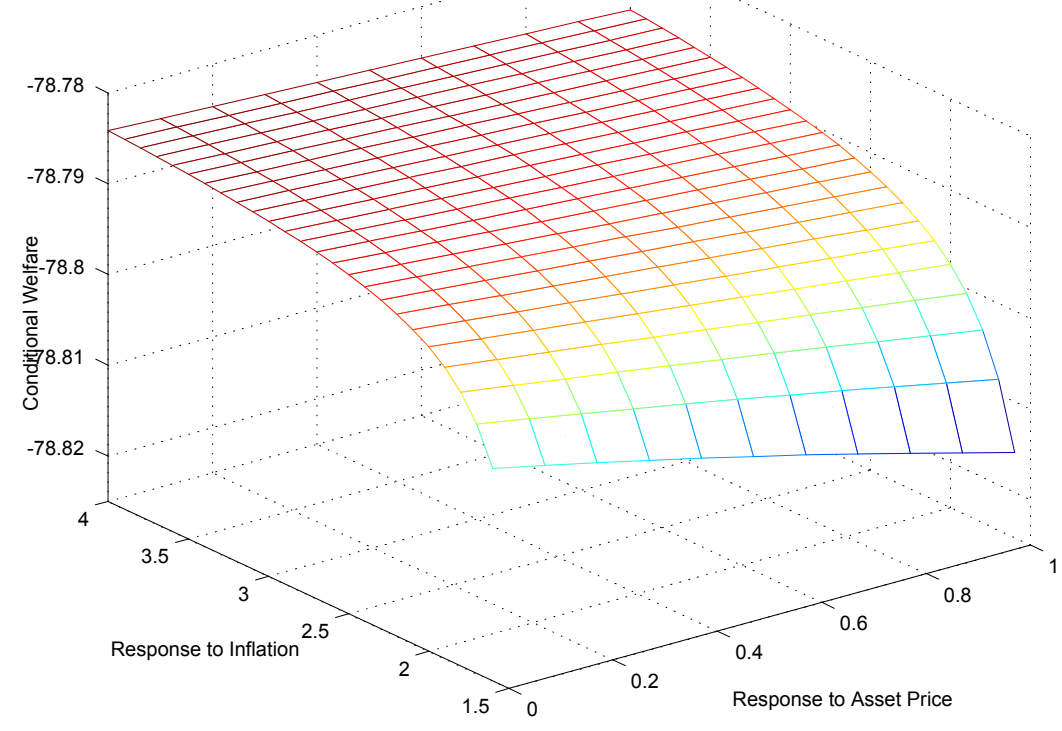

Figure 8: Effect on Welfare of Varying the Response to Inflation and Asset Price (IP model, no-smoothing)

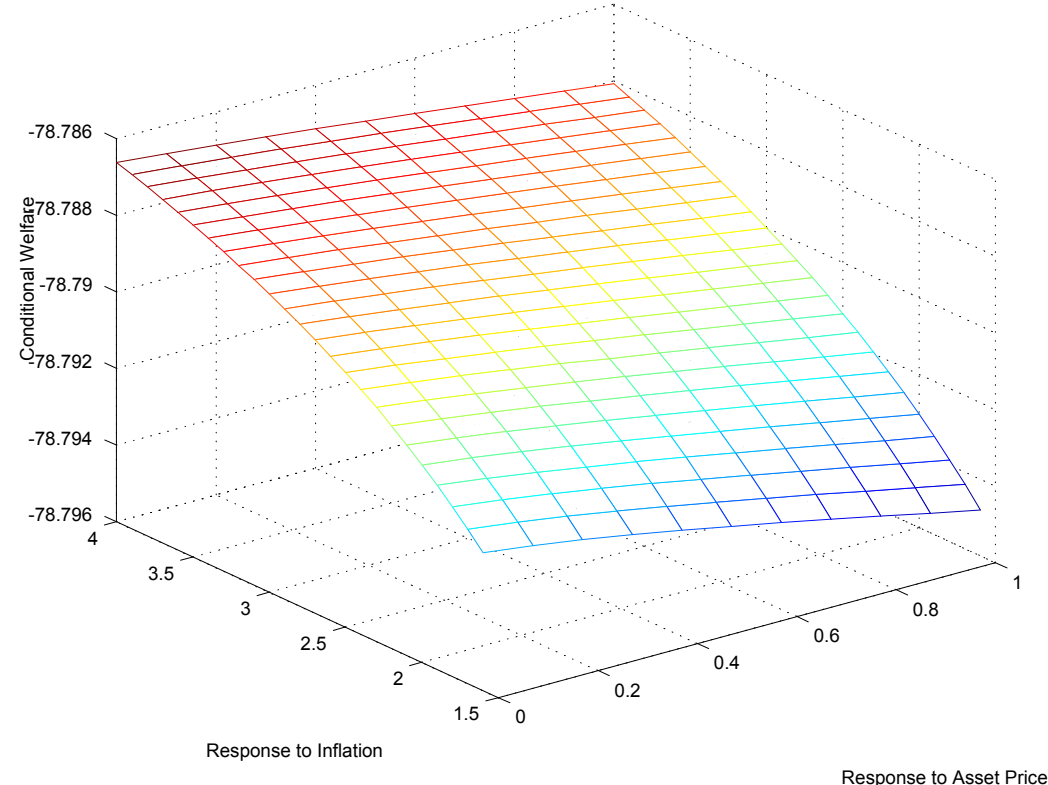

Figure 9: Effect on Welfare of Varying the Response to Inflation and Asset Price (IP model, smoothing) 